\title{
Frontier Efficiency Methodologies to Measure Performance in the Insurance Industry: Overview, Systematization, and Recent Developments
}

\author{
Martin Eling a and Michael Luhnen ${ }^{\mathrm{b}}$ \\ ${ }^{a}$ Institute of Insurance Science, Ulm University, Helmholtzstraße 22, 89069 Ulm, Germany. \\ ${ }^{\mathrm{b}}$ Institute of Insurance Economics, University of St. Gallen, Kirchlistrasse 2, 9010 St. Gallen, Switzerland.
}

The purpose of this paper is to provide an overview on frontier efficiency measurement in the insurance industry, a topic of great interest in the academic literature during the last several years. We provide a comprehensive survey of 95 studies with a special emphasis on innovations and recent developments. We review different econometric and mathematical programming approaches to efficiency measurement in insurance and discuss the choice of input and output factors. Furthermore, we categorise the 95 studies into 10 different areas of application and discuss selected results. While there is a broad consensus with regard to the choice of methodology and input factors, our review reveals large differences in output measurement. Significant need for future research can be identified, for example, with regard to analysis of organisational forms, market structure and risk management, especially in the international context.

The Geneva Papers (2010) 35, 217-265. doi:10.1057/gpp.2010.1

Keywords: efficiency; data envelopment analysis; stochastic frontier analysis

\section{Introduction}

Academics as well as practitioners in the insurance sector have spent significant resources in the last years to develop management techniques appropriate for the rapidly changing marketplace. New regulatory requirements, increasing competition, and the recent dynamics in capital markets have all fundamentally changed the business environment that insurers are active in. In such rapidly changing markets, shareholders and managers need accurate and reliable information about the value generated by their business activities. As a result most insurance companies have adopted modern management techniques such as shareholder value or value-based management. Benchmarking techniques can be used in a variety of ways to assist firms in evaluating whether they are performing better or worse than their peers in terms of technology, scale, cost minimisation, and revenue maximisation. They can be used to direct management efforts to the areas that need improvement, to identify attractive targets for mergers and acquisitions (M\&A), and for many other purposes. Performance measurement can also be used within the firm to compare the performance of departments, divisions, branches, and agencies.

In this paper, we focus on a new class of benchmarking techniques called frontier efficiency methodologies. Frontier methodologies measure firm performance relative to "best practice" frontiers comprised of the leading firms in the industry. They are 
superior to traditional techniques such as financial ratio analysis because they summarise performance in a single statistic that controls for differences among firms using a sophisticated multidimensional framework (see Cummins and Weiss ${ }^{1}$ ).

Efficiency measurement is one of the most rapidly growing streams of literature and the insurance sector in particular has seen extreme growth in the number of studies applying frontier efficiency methods. Berger and Humphrey ${ }^{2}$ and Cummins and Weiss ${ }^{1}$ surveyed eight and 21 studies, respectively. Now, less than 10 years after the Cummins/Weiss survey, we find 95 studies on efficiency measurement in the insurance industry. Recent work in the field has refined methodologies, addressed new topics (e.g., market structure and risk management), and extended geographic coverage from a previously U.S.-focused view to a broad set of countries around the world, including emerging markets such as China and Taiwan.

The aim of this paper is to provide a comprehensive survey of these 95 studies on frontier efficiency measurement in insurance with a special emphasis on innovations and recent developments. We review different econometric and mathematical programming approaches to efficiency measurement in insurance and discuss the choice of input and output factors. Furthermore, we categorise the 95 studies into 10 different areas of application and discuss selected results.

Our four main results can be summarised as follows. (1) Data envelopment analysis (DEA) is the most frequently applied method of frontier efficiency analysis in insurance. In recent years, however, there have been many proposals for refining and further developing methodologies, for example, by applying more appropriate functional forms for the econometric approaches. (2) There is a widespread agreement with regard to the choice of input factors; most studies define, at a minimum, labour, capital, and business services (or an equivalent) as inputs of an insurance company. There is also agreement with regard to output measurement; most studies employ the so called value-added approach. However, there is disagreement among researchers as to whether premiums or claims are the more adequate proxy for value added. (3) There has been a recent expansion to new fields of application such as market structure and risk management. Also, geographic scope has noticeably expanded beyond its former U.S. focus to encompass a broad array of countries - 45 according to our surveyincluding emerging markets such as China, Taiwan, and Malaysia. (4) Finally, we identify significant need for future research, for example, especially in the field of organisational form, market structure, risk management, and with regard to different lines of business. As most studies focus on U.S. insurance markets, significant research opportunities in international insurance markets are highlighted.

This paper contributes to the academic literature on frontier efficiency measurement for insurance in several ways: Apart from providing a comprehensive overview of this strongly growing body of literature, we conduct a systematisation of the different applications of frontier efficiency measurement in insurance. Moreover, we study recent innovations with regard to methodology and application and identify fields for future research. Thus, this paper serves as an overview for researchers in the field as

\footnotetext{
${ }^{1}$ Cummins and Weiss (2000).

${ }^{2}$ Berger and Humphrey (1997).
} 
well as for regulators and managers interested in the results and implications of frontier efficiency studies.

The remainder of the paper is organised as follows. "Overview of efficiency measurement in the insurance industry" section starts with an overview of the 95 studies focusing on frontier efficiency in the insurance industry, subdivided in 10 application areas. The "Frontier efficiency methodologies" section introduces the two principal methodological approaches to efficiency measurement, surveys their implementation in insurance studies, and highlights recent innovations. The "Input and output factors used in efficiency measurement" section contains an overview on the usage of input and output factors. In the "Fields of application in efficiency measurement" section, we get back to 10 application areas and discuss the most important findings from the 95 studies. Finally, the "Conclusion and implications for future research" section concludes and highlights options for future research.

\section{Overview of efficiency measurement in the insurance industry}

The following overview of 95 papers (63 published articles, 32 working papers) builds upon and significantly extends two earlier surveys of efficiency measurement literature in the financial services industry: One by Berger and Humphrey, ${ }^{2}$ which focuses on banks. The second one by Cummins and Weiss ${ }^{1}$ focuses on the insurance industry and covers 21 studies that have been published until the year 1999. Three studies (Weiss; ${ }^{3}$ Bernstein $^{4}$ ) that are considered in Cummins and Weiss ${ }^{1}$ have been excluded from this overview since they are not efficient frontier based, but focus on productivity (these studies are included in an extended overview that we present in the Appendix).

Table 1 is arranged according to 10 different application areas (first column). Some of these application areas have been selected following Berger and Humphrey's ${ }^{2}$ overview for the banking sector. However, we extended and refined their systematisation to account for the specifics of the insurance sector. Although many studies make contributions to more than one topic, we tried to focus on the primary field of application. A more detailed table with information, such as input and output factors, types of efficiencies analysed, sample periods, lines of business covered, and main findings, is included in the Appendix. ${ }^{5}$

\section{Frontier efficiency methodologies}

Frontier efficiency methodologies measure the performance of a company relative to a "best practice" frontier, which (in the case of single input/output) is determined by the most efficient companies in the industry. The efficiency score is usually standardised between 0 and 1 , with the most (least) efficient firm receiving the value of $1(0)$. The difference between a company's assigned value and the value of 1 can be interpreted as

\footnotetext{
${ }^{3}$ Weiss $(1986,1991 b)$.

${ }^{4}$ Bernstein (1999).

${ }^{5}$ In order to identify and summarize articles, we have specified a search strategy based on a list of relevant keywords, journals, databases, and authors. All details on the search strategy are available upon request.
} 
Table 1 Studies on efficiency in the insurance industry

\begin{tabular}{|c|c|c|c|}
\hline Application & Country & Method & Author (date) \\
\hline \multirow{6}{*}{$\begin{array}{l}\text { Distribution } \\
\text { systems }\end{array}$} & U.S. & DFA & Berger et al. (1997) \\
\hline & U.S. & DEA & Brockett et al. (1998) \\
\hline & U.S. & DEA & Carr et al. (1999) \\
\hline & U.K. & SFA & Klumpes (2004) \\
\hline & Germany & DEA & Trigo Gamarra and Growitsch (2008) \\
\hline & U.K. & SFA & Ward (2002) \\
\hline \multirow{3}{*}{$\begin{array}{l}\text { Financial and risk } \\
\text { management, capital } \\
\text { utilization }\end{array}$} & U.S. & DEA & Brockett et al. (2004a) \\
\hline & U.S. & SFA & Cummins et al. (2006) \\
\hline & U.S. & DEA & Cummins and Nini, 2002 \\
\hline \multirow{23}{*}{$\begin{array}{l}\text { General level of } \\
\text { efficiency and } \\
\text { evolution over time }\end{array}$} & Portugal & DEA & Barros et al. (2005) \\
\hline & Nigeria & DEA & Barros and Obijiaku (2007) \\
\hline & The Netherlands & SFA & Bikker and van Leuvensteijn (2008) \\
\hline & U.S. & DEA & Cummins (1999) \\
\hline & Tunisia & DEA, SFA & Chaffai and Ouertani (2002) \\
\hline & Italy & DEA & Cummins et al. (1996) \\
\hline & U.S. & SFA & Cummins and Weiss (1993) \\
\hline & France & DEA, SFA & Fecher et al. (1993) \\
\hline & U.S. & DFA & Gardner and Grace (1993) \\
\hline & Taiwan & DFA & Нао (2007) \\
\hline & Taiwan & DFA, SFA & Hao and Chou (2005) \\
\hline & U.K. & SFA & Hardwick (1997) \\
\hline & China & SFA & Huang (2007) \\
\hline & Germany & DEA & Kessner and Polborn (1999) \\
\hline & China & DEA & Leverty et al. (2004) \\
\hline & Germany & DEA & Luhnen (2008) \\
\hline & Malaysia & DEA & Mansor and Radam (2000) \\
\hline & Greece & DEA & Noulas et al. (2001) \\
\hline & China & DEA & Qiu and Chen (2006) \\
\hline & India & DEA & Tone and Sahoo (2005) \\
\hline & U.S. & SFA & Weiss (1991a) \\
\hline & Australia & DEA & Worthington and Hurley (2002) \\
\hline & China & DEA & Yao et al. (2007) \\
\hline \multirow{10}{*}{$\begin{array}{l}\text { Intercountry } \\
\text { comparisons }\end{array}$} & France, Belgium & DEA, SFA & Delhausse et al. (1995) \\
\hline & 6 European countries & DEA & Diacon (2001) \\
\hline & 15 European countries & DEA & Diacon et al. (2002) \\
\hline & 15 OECD countries & DEA & Donni and Fecher (1997) \\
\hline & 36 countries & DEA, SFA & Eling and Luhnen (2008) \\
\hline & Germany, U.K. & DEA & Kessner (2001a) \\
\hline & Austria, Germany & DEA & Mahlberg (1999) \\
\hline & 11 OECD countries & DFA, SFA & Rai (1996) \\
\hline & 18 European countries & SFA & Vencappa et al. (2008) \\
\hline & 14 European countries & SFA & Zanghieri (2008) \\
\hline \multirow[t]{3}{*}{ Market structure } & U.S. & SFA & Choi and Weiss (2005) \\
\hline & U.S. & SFA & Choi and Weiss (2008) \\
\hline & 14 European countries & SFA & Fenn et al. (2008) \\
\hline
\end{tabular}


Table 1 (continued)

\begin{tabular}{|c|c|c|c|}
\hline Application & Country & Method & Author (date) \\
\hline \multirow[t]{5}{*}{ Mergers } & U.S. & DEA & Cummins et al. (1999a) \\
\hline & U.S. & DEA & Cummins and Xie (2008) \\
\hline & 7 European countries & DEA & Davutyan and Klumpes (2008) \\
\hline & U.S. & DFA & Kim and Grace (1995) \\
\hline & 7 European countries & DEA & Klumpes (2007) \\
\hline \multirow{9}{*}{$\begin{array}{l}\text { Methodology issues, } \\
\text { comparing different } \\
\text { techniques or } \\
\text { assumptions }\end{array}$} & U.S. & DEA & Brockett et al. (2004b) \\
\hline & U.S. & $\begin{array}{l}\text { DEA, DFA, } \\
\text { FDH, SFA }\end{array}$ & Cummins and $\mathrm{Zi} \mathrm{(1998)}$ \\
\hline & Spain & SFA & Fuentes et al. (2001) \\
\hline & Japan & DEA & Fukuyama and Weber (2001) \\
\hline & Taiwan & DEA & Hwang and Kao (2008a) \\
\hline & Taiwan & DEA & Hwang and Kao (2008b) \\
\hline & U.S. & DEA & Leverty and Grace (2008) \\
\hline & Canada & DEA & Wu et al. (2007) \\
\hline & Canada & DEA & Yang (2006) \\
\hline \multirow{13}{*}{$\begin{array}{l}\text { Organisational } \\
\text { form, corporate } \\
\text { governance issues }\end{array}$} & U.S. & DEA & Brockett et al. (2005) \\
\hline & Spain & DEA & Cummins et al. (2004) \\
\hline & U.S. & DEA & Cummins et al. (1999b) \\
\hline & Germany & DEA & Diboky and Ubl (2007) \\
\hline & Belgium & $\mathrm{FDH}$ & Donni and Hamende (1993) \\
\hline & U.S. & DEA & Erhemjamts and Leverty (2007) \\
\hline & Japan & DEA & Fukuyama (1997) \\
\hline & U.S. & SFA & Greene and Segal (2004) \\
\hline & U.K. & DEA & Hardwick et al. (2004) \\
\hline & Japan & DEA & Jeng and Lai (2005) \\
\hline & U.S. & DEA & Jeng et al. (2007) \\
\hline & Germany & DEA & Wende et al. (2008) \\
\hline & U.S. & DEA & Xie (2008) \\
\hline \multirow[t]{13}{*}{ Regulation change } & Ukraine & DEA & Badunenko et al. (2006) \\
\hline & $\begin{array}{l}\text { Korea, Philippines, } \\
\text { Taiwan, Thailand }\end{array}$ & DEA & Boonyasai et al. (2002) \\
\hline & Spain & DEA & Cummins and Rubio-Misas, 2006 \\
\hline & Austria & SFA & Ennsfellner et al. (2004) \\
\hline & Germany, U.K. & DEA, DFA & Hussels and Ward (2006) \\
\hline & Germany & DEA & Mahlberg (2000) \\
\hline & Germany & DEA & Mahlberg and Url (2000) \\
\hline & Austria & DEA & Mahlberg and Url (2003) \\
\hline & Germany, U.K. & DEA & Rees et al. (1999) \\
\hline & U.S. & DFA & Ryan and Schellhorn (2000) \\
\hline & Germany & SFA & Trigo Gamarra (2008) \\
\hline & Italy & DEA & Turchetti and Daraio (2004) \\
\hline & U.S. & SFA & Yuan and Phillips (2008) \\
\hline \multirow{5}{*}{$\begin{array}{l}\text { Scale and scope } \\
\text { economies }\end{array}$} & U.S. & TFA, SFA & Berger et al. (2000) \\
\hline & U.S. & DEA & Cummins et al. (2007) \\
\hline & France & SFA & Fecher et al. (1991) \\
\hline & Spain & SFA & Fuentes et al. (2005) \\
\hline & Japan & SFA & Hirao and Inoue (2004) \\
\hline
\end{tabular}


Table 1 (continued)

\begin{tabular}{llll}
\hline Application & Country & Method & Author (date) \\
\hline Ireland & DFA & Hwang and Gao (2005) \\
Germany & DEA & Kessner (2001b) \\
U.S. & DFA & Meador et al. (2000) \\
Finland & SFA & Toivanen (1997) \\
U.S. & SFA, TFA & Yuengert (1993) \\
\hline
\end{tabular}

Abbreviations: DEA: Data envelopment analysis; DFA: Distribution-free approach; FDH: Free disposal hull; SFA: Stochastic frontier approach; TFA: Thick frontier approach.

the company's improvement potential in terms of efficiency (see, e.g., Cooper et al. $^{6}$ ). Different types of efficient frontiers can be estimated. In the simplest case, a production frontier is estimated, assuming that companies minimise inputs conditional on given output levels (input-orientation) or maximise outputs conditional on given input levels (output-orientation).

There are two main approaches in efficient frontier analysis: the econometric approach and the mathematical programming approach. We shortly introduce these two approaches (including references to detailed overviews), discuss their application to the insurance field, and highlight recent innovations. ${ }^{7}$

\section{Econometric approaches}

The econometric approaches specify a production, cost, revenue, or profit function with a specific shape and make assumptions about the distributions of the inefficiency and error terms. There are three principal types of econometric frontier approaches. Although they all specify an efficient frontier form-usually translog, but also alternative forms such as generalised translog, Fourier flexible, or composite costthey differ in their distributional assumptions of the inefficiency and random components (see Cummins and Weiss ${ }^{1}$ ). The stochastic frontier approach assumes a composed error model where inefficiencies follow an asymmetric distribution (e.g., half-normal, exponential, or gamma) and the random error term follows a symmetric distribution, usually normal. The distribution-free approach (DFA) makes fewer specific assumptions, but requires several years of data. Efficiency of each company is assumed to be stable over time, and the random noise averages out to zero. Finally, the thick frontier approach does not make any distributional assumptions for the random error and inefficiency terms, but assumes that inefficiencies differ between the highest and lowest quartile firms (see, e.g., Kumbhakar and Lovell ${ }^{8}$ ).

\footnotetext{
${ }^{6}$ Cooper et al. (2007).

${ }^{7}$ Due to space constraints we restrict ourselves to a basic description of the methodologies and focus on recent developments and applications in the insurance industry. An extended version of this paper that contains more details on the different methodologies is available upon request.

${ }^{8}$ Kumbhakar and Lovell (2000).
} 
The most commonly used econometric approach is stochastic frontier analysis (SFA), which was first proposed by Aigner et al. ${ }^{9}$ SFA is usually applied in two steps: In the first step, a production, cost, revenue, or profit function is estimated, determining the efficient frontier. In the second step, for individual firms, deviations from the efficient frontier due to inefficiency and a random error are calculated (see Cummins and Weiss ${ }^{1}$ ). To illustrate SFA formally, we use a translog cost function that has been widely used in literature and shown to approximate the form of the real underlying cost function fairly well (see, e.g., Rai; ${ }^{10}$ Cummins and $\mathrm{Zi}^{1}{ }^{11}$ Cummins and Weiss; ${ }^{1}$ Choi and Weiss ${ }^{12}$ ):

$$
\ln C_{i}=\ln \hat{C}\left(p_{i}, y_{i}\right)+\varepsilon_{i}
$$

where $C_{i}$ are total observed costs of insurer $i . \ln \hat{C}\left(p_{i}, y_{i}\right)$, the $\log$ cost function that needs to be estimated contains a vector of input prices $p_{i}$ and a vector of output quantities $y_{i}$. The error term $\varepsilon_{i}$ shows how far an insurer is from the efficient frontier. The deviation might be due to two reasons and these are modelled as $\varepsilon_{I}=u_{i}+v_{i}$. The first reason, modelled by the first term $\left(u_{i}\right)$ are random deviations from the efficient frontier; usually, $u_{i}$ is assumed to be standard normally distributed. The second reason (modelled by the term $v_{i}$ ) is inefficiency, which is usually assumed to be half-normally distributed. To estimate efficiency, $\ln \hat{C}\left(p_{i}, y_{i}\right)$ is calculated using an econometric method, such as ordinary least squares or maximum likelihood. Then the residual is computed as:

$$
\ln C_{i}-\ln \hat{C}\left(p_{i}, y_{i}\right)=\varepsilon_{i}
$$

where $\varepsilon_{i}$ needs to be broken down into the components $u_{i}$ and $v_{i}$. This is done by finding the conditional probability distribution of $v_{i}$ given $\varepsilon_{i}$. Cost efficiency is then calculated as:

$$
\text { Efficiency }_{i t}=\frac{E\left(C_{i} \mid v_{i}=0, G_{i}\right)}{E\left(C_{i} \mid v_{i}, G_{i}\right)}
$$

where $C_{i}$ are total observed costs of insurer $i$ and $G_{i}$ is a vector of input prices and output quantities of insurer $i$. The numerator of Eq. (3) reflects minimum cost achievable, provided output and technology, if the insurer $i$ operates at full efficiency (i.e. $v_{i}=0$ ). The denominator shows actual costs of insurer $i$ given the actual level of efficiency.

There are two configuration decisions that must be made when employing SFA: (1) The choice of the functional form to approximate the real underlying production, cost, revenue, or profit function; and (2) the distributional assumption for the inefficiency term. The translog is an accepted and widely used functional form, but there are a variety of other options, including the Cobb-Douglas, Fuss normalised quadratic (see

\footnotetext{
${ }^{9}$ Aigner et al. (1979).

${ }^{10}$ Rai (1996).

${ }^{11}$ Cummins and Zi (1998).

${ }^{12}$ Choi and Weiss (2005).
} 
Morrison and Berndt ${ }^{13}$ ), and generalised translog (see Caves et al. ${ }^{14}$ ). The composite cost (see Pulley and Braunstein ${ }^{15}$ ) or the Fourier flexible form (see Gallant ${ }^{16}$ ) have also been applied in the financial services industry. While the random error term is usually assumed to be distributed normally, the inefficiency term has been specified to have different distributions, such as half-normal, truncated normal, exponential, or gamma (see, e.g., Berger and Humphrey ${ }^{2}$ ).

\section{Mathematical programming approaches}

Compared with the econometric approaches, the mathematical programming approaches put significantly less structure on the specification of the efficient frontier and do not decompose the inefficiency and error terms. The most widespread mathematical programming approach is "DEA", which uses linear programming to measure the relationship of produced goods and services (outputs) to assigned resources (inputs). DEA determines the efficiency score as an optimisation result. DEA models can be specified under the assumption of constant returns to scale (CRS) or variable returns to scale (VRS) and can be used to decompose cost efficiency into its single components - technical, pure technical, allocative, and scale efficiency. To illustrate DEA, we discuss a basic model for measuring technical efficiency assuming CRS (see, e.g., Cummins and Nini; ${ }^{17}$ Worthington and Hurley, ${ }^{18}$ Cooper et al. ${ }^{6}$ ). Efficiency $e$ of an insurer $i$ is measured by the ratio:

$$
e_{i}=\frac{s_{i}^{T} y_{i}}{r_{i}^{T} x_{i}},
$$

where $y_{i}$ is a vector with outputs, $j=y_{j, i}=1, \ldots, z$, of firm $i . x_{i}$ is a vector with inputs $x_{k, i}$, $k=1, \ldots, w . S_{i}^{T}$ is the transposed vector of output weights and $r_{i}^{T}$ the transposed vector of input weights. Input and output data are assumed to be positive. For each insurer $i$, the following optimisation problem must be solved in order to obtain optimal input and output weights for the maximisation of efficiency:

$$
\begin{aligned}
& \max _{s, r} e_{i}=\frac{s_{i}^{T} y_{i}}{r_{i}^{T} x_{i}}, \text { subject to : } \\
& \frac{s_{i}^{T} y_{i}}{r_{i}^{T} x_{i}} \leqslant 1 \\
& s_{j, i}, r_{k, i} 0, \forall j=1, \ldots, z, k=1, \ldots, w .
\end{aligned}
$$

\footnotetext{
${ }^{13}$ Morrison and Berndt (1982).

${ }^{14}$ Caves et al. (1980).

15 Pulley and Braunstein (1992).

${ }^{16}$ Gallant (1982).

${ }^{17}$ Cummins and Nini (2002).

${ }^{18}$ Worthington and Hurley (2002).
} 
The first condition of Eq. (5) limits the ratio $e_{i}$ of weighted outputs to weighted inputs to a maximum of 1 . Since the fractional program (Eq. (5)) has an infinite number of solutions, it must be transformed into a linear programme by imposing the constraint $r_{i}^{T} x_{i}=1$, implying that the weighted sum of inputs is standardised to 1 :

$$
\begin{aligned}
& \max _{s, r} e_{i}=s_{i}^{T} y_{i}, \text { subject to : } \\
& r_{i}^{T} x_{i}=1 \\
& s_{i}^{T} y_{i}-r_{i}^{T} x_{i} \leqslant 0 \\
& s_{j, i}, r_{k, i} 0, \forall j=1, \ldots, z, k=1, \ldots, w .
\end{aligned}
$$

The free-disposal hull (FDH) approach is a special configuration of DEA. Under this approach, the points on the lines connecting the DEA vertices are excluded from the frontier and the convexity assumption on the efficient frontier is relaxed (see Cooper et al. ${ }^{6}$ ).

\section{Total Factor Productivity}

The concept of total factor productivity is closely related to efficiency and often used in efficiency studies. Productivity is an index that relates the total amount of outputs produced to the total amount of inputs used in the production process (see Cummins and Weiss (p. 770)). Total factor productivity growth is thus measured as the change in total outputs net of the change in total input usage. In contrast, the concept of efficiency measures inputs and outputs in relation to a benchmark, that is, the optimal inputoutput usage in an industry. Of special interest is the Malmquist index of total factor productivity, since many of the reviewed studies work with this measure in combination with DEA analysis (see, e.g., Cummins et al.; ${ }^{19}$ Cummins and Rubio-Misas ${ }^{20}$ ). The important feature of the Malmquist index is that it is able to decompose total factor productivity growth into two elements: Technical efficiency changes to determine how much the distance of an individual firm to the efficient frontier has changed, and technical change to determine the movements of the efficient frontier itself due to technical change over time (see Grosskopf; ${ }^{21}$ Cummins and Weiss ${ }^{1}$ ). Overall, the total factor productivity growth is relatively lower in the insurance industry, especially compared to manufacturing industries (Bernstein; ${ }^{4}$ Fuentes et al.; ${ }^{22}$ Luhnen $^{23}$ ).

\section{Comparison and discussion of recent developments}

Both the econometric and mathematical programming approaches have their advantages and disadvantages and there is no consensus as to which method is

\footnotetext{
${ }^{19}$ Cummins et al. (1999b).

${ }^{20}$ Cummins and Rubio-Misas (2006).

${ }^{21}$ Grosskopf (1993)

${ }^{22}$ Fuentes et al. (2001).

${ }^{23}$ Luhnen (2008).
} 
superior (see, e.g., Cummins and $\mathrm{Zi}^{11}$ Hussels and Ward $^{24}$ ). The econometric approach has the main disadvantage of using strong assumptions regarding the form of the efficient frontier. It assumes a specific functional form, such as the translog or composite cost, and therefore expects a certain underlying economic behaviour, which may not be valid. The mathematical programming approach thus has the advantage of imposing less structure on the efficient frontier. However, compared to the econometric approach, it has the disadvantage of not taking into account a random error term. Consequently, mathematical programming approaches run the risk of taking all deviations from the efficient frontier as inefficiencies, therefore possibly mistaking a true random error for inefficiency (see Berger and Humphrey ${ }^{2}$ ).

In empirical studies, the DEA approach has been most frequently used. Out of the 95 surveyed studies, 55 use DEA, 22 SFA, seven DFA, and one FDH. Ten studies follow the advice given by Cummins and $\mathrm{Zi}^{11}$ and consider multiple approaches, ideally from both the econometric and mathematical programming sides. Most of these find highly correlated results when ranking firms by their relative efficiency according to different approaches (see, e.g., Hussels and $\mathrm{Ward}^{24}$ ). However, both approaches illuminate efficiency from different perspectives and thus deliver different insights. This is why we follow Cummins and $\mathrm{Zi}^{11}$ and recommend considering both DEA and SFA in empirical studies. Given significant increases in computer power and availability of software for both these approaches makes a combined analysis feasible and the interpretation of the empirical findings much richer.

For DEA, the most widely used specifications have been under the assumption of VRS. For SFA, most studies chose the translog functional form. Total factor productivity has been calculated by 24 studies - in combination with DEA in 21 cases and with SFA in three cases. The choice of methods is often determined by the available data. For example, if the available data are known to be noisy, the econometric approach, featuring an error term to accommodate noise, may lead to more accurate results. In this case, the mathematical programming approach would not be appropriate, since it mistakes the noise as inefficiencies due to the fact that there is no error term (see Cummins and Weiss ${ }^{1}$ ).

In recent years, there have been a number of proposals for the improvement of efficiency measurement in the field of insurance. For the econometric approach, a major direction has been to apply more flexible specifications of the functional form. Examples are the composite cost function or the Fourier flexible distribution (see, e.g., Fenn et al. ${ }^{25}$ ). Also, Bayesian stochastic frontier models (see Van den Broeck et al. ${ }^{26}$ ), featuring advantages, such as exact small-sample inference on efficiencies, have been applied (see, e.g., Ennsfellner et al. ${ }^{27}$ ). A further proposal has been made regarding the incorporation of firm-specific variables into the estimation process. Instead of using a two-stage approach, which first estimates inefficiency of sample firms and then examines the association of inefficiency with firm-specific variables through

\footnotetext{
${ }^{24}$ Hussels and Ward (2006).

${ }^{25}$ Fenn et al. (2008).

${ }^{26}$ Van den Broeck et al. (1994).

${ }^{27}$ Ennsfellner et al. (2004).
} 
regressions, a one-stage approach is suggested. In this approach, the estimated frontier directly takes into account firm-specific variables by modelling mean inefficiency as a function of firm-specific variables (conditional mean approach, see, e.g., Huang and Liu; ${ }^{28}$ Greene and Segal ${ }^{29}$ ). Fenn et al. ${ }^{25}$ address the drawback of the conditional mean approach, that the variance of the random and efficiency errors is assumed constant. Following a procedure by Kumbhakar and Lovell, ${ }^{8}$ they explicitly model the variance of both types of errors and thus correct for potential heteroscedasticity.

Another contribution has been made with regard to the Malmquist index of total factor productivity. Although this index is usually applied to non-parametric DEA for insurance companies, Fuentes et al. ${ }^{22}$ develop a parametric distance function that enables them to calculate the Malmquist index also for the econometric approach. They show that using the estimated regression parameters, several radial distance functions can be calculated and combined in order to estimate and decompose the productivity index.

A drawback of the mathematical programming approach has been the lack of statistical properties. But Banker ${ }^{30}$ has shown that DEA estimators can also be interpreted as maximum likelihood estimators under certain conditions, providing a statistical base to DEA. However, the sampling distribution of the underlying DEA efficiency estimators stays unknown (see, e.g., Berger and Humphrey ${ }^{2}$ ). Also, DEA efficiency estimates have been shown to be biased upward in finite examples (see, e.g., Simar and Wilson ${ }^{31}$ ). In this context, the bootstrapping procedure proposed by Simar and Wilson ${ }^{31}$ has been applied to the insurance industry. It provides an empirical approximation of the sampling distribution of efficiency estimates and corrects the upwards bias (see, e.g., Cummins et al.;2 Diboky and Ubl; ${ }^{33}$ Erhemjamts and Leverty $^{34}$ ). Simar and Wilson ${ }^{35}$ also introduce a truncated regression and bootstrapping procedure that allows to investigate the impact of external variables on efficiency scores permitting valid inference, as opposed to the commonly used Tobit regression approaches.

A further innovation is the introduction of cross-frontier efficiency analysis, which estimates efficiency of firms using one particular technology relative to the best practice frontier of firms using an alternative technology. Cross-frontier efficiency analysis makes it possible to determine whether the outputs of one specific technology could be produced more efficiently by using the alternative technology. Cross-frontier analysis has been used to examine the efficiency of different organisational forms, comparing technical, cost, and revenue efficiency of stocks and mutual insurers (see Cummins et $a{ }^{36}{ }^{36}$. It has also been used for the analysis of scope economies,

\footnotetext{
${ }^{28}$ Huang and Liu (1994).

${ }^{29}$ Greene and Segal (2004).

${ }^{30}$ Banker (1993).

${ }^{31}$ Simar and Wilson (1998).

${ }^{32}$ Cummins et al. (2007).

33 Diboky and Ubl (2007).

${ }^{34}$ Erhemjamts and Leverty (2007).

${ }^{35}$ Simar and Wilson (2007).

${ }^{36}$ Cummins et al. (1999b, 2003, 2004).
} 
comparing diversified and specialist firms (see Cummins et al. ${ }^{32}$ ). Finally, Brocket et al. ${ }^{37}$ apply a range-adjusted measure version of DEA to the insurance industry. This DEA version, in contrast to other DEA models, offers the advantage of being able to produce efficiency rankings suitable for significance tests such as the Mann-Whitney statistic.

\section{Input and output factors used in efficiency measurement}

\section{Choice of input factors}

There are three main insurance inputs: labour, business services and materials, and capital. Labour can be further divided into agent and home-office labour. The category of business services and materials is usually not further subdivided, but includes items like travel, communications, and advertising. At least three categories of capital can be distinguished: physical, debt, and equity capital (see Cummins et al.; ${ }^{38}$ Cummins and Weiss ${ }^{1}$ ). Data on the number of employees or hours worked are not publicly available for the insurance industry in most cases. Therefore, in order to proxy labour and business service input, input quantities are derived by dividing the expenditures for these inputs with publicly available wage variables or price indices. For example, the U.S. Department of Labour data on average weekly wages for SIC Class 6,311 (home-office life insurance labour), can be used in the case of studying the U.S. insurance industry (see, e.g., Berger et al.; ${ }^{39}$ Cummins and $\mathrm{Zi}^{11}$ ). Physical capital is often included in the business service and materials category, but debt and equity capital are important inputs for which adequate cost measures have to be found (see, e.g., Cummins et al. ${ }^{19}$ ).

Sixty-one out of 95 studies use at least labour and capital as inputs and most of them also add a third category (miscellaneous, mostly business services). Out of those 61 studies, 18 differentiate between agent and non-agent labour. Also, the number of studies differentiating between equity and debt capital is low; only 16 do so. Regarding the 34 contributions that do not employ the standard input categories, 21 of them incorporate broader expenditure categories as inputs - for example, total operating expenses-without decomposing them into quantities and prices (see, e.g., Rees et al.;0 Mahlberg and $\mathrm{Url}^{41}$ ). Nine studies do not cover capital explicitly, that is, they consider labour only or labour and an additional composite category. Finally, four studies that focus on financial intermediation consider only capital-related inputs (see, e.g., Brocket et $a l^{42}$ ). The choice of input prices is mainly determined by the data that are publicly available in the countries under investigation.

\footnotetext{
${ }^{37}$ Brocket et al. (2005).

${ }^{38}$ Cummins et al. (1999a).

39 Berger et al. (1997).

${ }^{40}$ Rees et al. (1999).

${ }^{41}$ Mahlberg and Url (2003).

42 Brocket et al. (1998).
} 


\section{Choice of output factors}

There are three principal approaches to measure outputs. The intermediation approach views the insurance company as a financial intermediary that manages a reservoir of assets, borrowing funds from policy-holders, investing them on capital markets, and paying out claims, taxes, and costs (see Brocket et al.;2 also called flow approach; see Leverty and Grace $^{43}$ ). The user-cost method differentiates between inputs and outputs, based on the net contribution to revenues. If a financial product yields a return that exceeds the opportunity cost of funds or if the financial costs of a liability are less than the opportunity costs, it is deemed a financial input. Otherwise, it is considered a financial output (see Hancock; ${ }^{44}$ Cummins and Weiss ${ }^{1}$ ). The value-added approach (also called production approach; see Grace and Timme; ${ }^{45}$ Berger et al. ${ }^{46}$ ) counts outputs as important if they contribute a significant added value, based on operating cost allocations (see Berger et $a .^{46}{ }^{4}$ ). Usually, several types of outputs are defined, representing the single lines of business under review.

The value-added approach assumes that the insurer provides three main services, for which volume output proxies must be defined: Through the first service, risk-pooling and risk-bearing, insurers create value added by operating a risk pool, collecting premiums from policy-holders, and redistributing most of them to customers who have incurred losses. Via the second service, "real" financial services relating to insured losses, insurers create added value for their policy-holders by providing real services such as financial planning (life) or the design of coverage programs (propertyliability). The third service is intermediation; insurers create added value by acting as financial intermediaries that invest the premiums provided by the policy-holders, for example, on the capital market and pays out claims and administrative expenses (see, e.g., Cummins and Nini ${ }^{17}$ ).

To proxy the risk-pooling/risk-bearing function, either premiums or incurred benefits (life) and present value of losses (property-liability) have been used. Different output proxies are thus used for life and property-liability insurers, reflecting differences in the types of insurance and data availability (see Berger et $a l .{ }^{39}$ ). In literature, there is an intense debate as to whether premiums are an appropriate proxy because they represent price times quantity of output and not output (see, e.g., Yuengert ${ }^{47}$ ). The present value of real losses incurred, however, can be used as a reasonable proxy for output as it corresponds closely to the theoretical measures used in insurance economics (see Cummins and Weiss, ${ }^{1}$ for a theoretical derivation based on the Pratt-Arrow concept of the insurance premium). The risk-pooling/risk-bearing function involves collecting funds from everyone in the risk pool and redistributing it to policy-holders that incur losses. Thus, losses represent the total amount redistributed by the pool and are a useful risk proxy (see Berger et al. ${ }^{39}$ ). In life insurance, incurred benefits represent payments received by policy-holders in the current year;

\footnotetext{
${ }^{43}$ Leverty and Grace (2008).

${ }^{44}$ Hancock (1985).

45 Grace and Timme (1992).

${ }^{46}$ Berger et al. (2000).

47 Yuengert (1993).
} 
they measure the amount of funds pooled by insurers and redistributed to policyholders as compensation for insured events and are thus comparable to the loss proxy in property-liability insurance. Insurers issue debt contracts (insurance policies and annuities) and invest the funds until they are withdrawn by policy-holders (in the case of asset accumulation products sold by life insurers) or are needed to pay claims (see Cummins and Weiss ${ }^{1}$ ). Additions to reserves or invested assets are thus good proxies for the intermediation function and often used in literature (see, e.g., Cummins et al.; ${ }^{19}$ Berger et $a l .{ }^{39}$ ). Both incurred benefits/present value of losses, as well as additions to reserves/invested assets, are correlated with the third function, real financial services of the insurer.

\section{Comparison and discussion of recent developments}

The value-added approach has been established as best practice; 80 out of 95 studies apply this approach (see Appendix). However, there is a debate among those using the value-added approach as to whether claims/benefits or premiums/sum insured are the most appropriate proxy for value added. Out of the 80 articles, 46 follow Cummins and Weiss ${ }^{1}$ and specify output as either claims/present value of claims (propertyliability) or benefits/net incurred benefits (life). 32 studies specify output as premiums/ sum insured. Two studies use both proxies - claims for non-life and premiums for life insurance. One study uses neither of the two main proxies: Yuengert ${ }^{47}$ takes reserves/ additions to reserves as a proxy for value added. Although more studies use claims/ benefits to proxy output than premiums/sum insured, there is no recognisable trend over time as to whether either of the two main proxies is gaining more of a following among researchers. ${ }^{48}$

Since the value-added approach to output measurement dominates the literature, there have only been few innovations with regard to output measurement. Hwang and $\mathrm{KaO}^{49}$ introduce a new relational two-stage production process, in which the outputs of the first production stage, called "premium acquisition", are the inputs for the second production stage, called "profit generation". Regarding the other two approaches for output measurement, five studies employ the intermediation approach, for example, taking return on investment (ROI), liquid assets to liability, and solvency scores as outputs (see Brocket et al. ${ }^{50}$ ).

A reflection of popularity is not necessarily an indication of validity. A good example is the controversial discussion in literature on value added vs. financial intermediation approaches (Brocket et al.; ${ }^{51}$ Leverty and Grace $^{43}$ ). Cummins and Weiss ${ }^{1}$ argues that the financial intermediation approach is not optimal because insurers provide many services in addition to financial intermediation. Leverty and

${ }^{48}$ We categorized the number of studies by usage of output proxy and year of publication: from 1991 to 1995, three studies use claims/benefits and five use premiums/sum insured; 1996-2000: 12/7; 2001-2005: 12/12; 2006-2008: 15/7. Premiums/sum insured might be used in many studies because these measures are more readily available for most countries.

${ }^{49}$ Hwang and Kao $(2008 \mathrm{a}, \mathrm{b})$.

${ }^{50}$ Brocket et al. (2004a, b, 2005).

51 Brocket et al. (2005). 
Grace $^{43}$ show that the value-added approach is consistent with traditional measures of firm performance and inversely related to insurer insolvency. The intermediation approach is only weakly related to traditional performance measures and firms recognised as highly efficient have a higher probability to fail. In the light of these results it seems quite reasonable to prefer the value-added approach over the financial intermediation approach.

None of the studies reviewed uses the user-cost approach, because this approach requires precise data on product revenues and opportunity costs, which are not available in the insurance industry (see Klumpes ${ }^{52}$ ). Five studies use both the valueadded and intermediation approaches (see, e.g., Jeng and Lai ${ }^{53}$ Leverty and Grace ${ }^{43}$ ). Two studies apply physical outputs, for example, Toivanen ${ }^{54}$ uses number of product units produced as insurance output.

\section{Fields of application in efficiency measurement}

Frontier efficiency methods have been applied to a wide range of countries as well as to all major lines of business. Furthermore, frontier efficiency methods have been used to investigate various economic questions. These include risk management, market structure, organisational forms, and mergers. However, it should be noted that findings regarding the same economic issues often vary depending on country, line of business, time horizon, and method considered in the different studies. In the following, we analyse the 95 studies of our survey according to their field of application and selected main results. For this purpose, we consider ten application categories (see Table 1). As a quick overview, Table 2 summarises the main findings that are discussed in more detail below.

\section{Distribution systems}

Two main hypotheses have been developed to explain the coexistence of distribution systems in the insurance industry (see Berger et al $^{39}$ ). According to the marketimperfections hypothesis, independent-agency insurers survive while providing essentially the same services as direct-writing insurers because of market imperfections, such as, for example, price regulation or search costs. In contrast, according to the product-quality hypothesis, the higher costs of independent-agency insurers can be justified with higher product quality or greater service intensity, for example, by providing additional customer assistance with claims settlement or offering a greater variety of product choices.

While these two hypotheses argue in favour of coexistence, the empirical evidence is mixed. Brockett et al., ${ }^{55}$ studying the U.S., and Klumpes, ${ }^{56}$ studying the U.K., find

\footnotetext{
52 Klumpes (2007).

53 Jeng and Lai (2005).

54 Toivanen (1997).

55 Brockett et al. (1998, 2004a).

${ }^{56}$ Klumpes (2004).
} 
Table 2 Main findings from the 95 studies

\begin{tabular}{ll}
\hline Application & Findings \\
\hline Distribution systems & - In most studies, independent agent distribution systems are more efficient \\
than direct systems (Brockett et al. (1998, 2004a, b); Klumpes, 2004) \\
- Insurers with one distribution system are more efficient than those \\
employing more than one (Ward, 2002) \\
Financial and risk & - Risk management and financial intermediation increase efficiency \\
management, capital & (Cummins et al., 2006) \\
utilisation & - Solvency scores have limited impact on efficiency (Brockett et al., 2004a, b) \\
General level of efficiency & - Significant levels of inefficiency with corresponding room for improvement, \\
and evolution over time & for example, for Nigeria, Tunisia, Malaysia \\
Intercountry comparisons & - Striking international differences in average efficiency, for example, Nigeria \\
& (see Barros and Obijiaku, 2007), Tunisia (see Chaffai and Ouertani, 2002), \\
& Malaysia (see Mansor and Radam, 2000), or Australia (see Worthington \\
- & End Hurley, 2002) \\
& Efficiency in developed countries is on average higher than that in emerging \\
& around the world (Eling and Luhnen, 2008)
\end{tabular}

Mergers

Methodology issues, comparing different techniques or assumptions

Organisational form, corporate governance issues

Regulation change

Scale and scope economies
- Mergers are beneficial for the efficiency of acquiring and target firm (Cummins et al. (1999a); Cummins and Xie (2008)

- Mergers and acquisitions, facilitated by the liberalised EU market, have led to efficiency gains (Fenn et al., 2008)

- Average efficiencies can differ significantly across methods (Cummins and $\mathrm{Zi}, 1998)$

- The value-added and intermediation approaches to efficiency measurement are not consistent (Leverty and Grace, 2008)

- Most authors find that stock companies are more efficient than mutuals (Cummins et al., 1999a)

- Efficiency improvements after demutualisation were identified (Jeng et al., 2007)

- Modest efficiency improvements from deregulation in Europe (Rees et al., 1999; Hussels and Ward, 2006)

- Efficiency gains in Asia due to deregulation (Boonyasai et al., 2002)

- No efficiency change with risk-based capital requirements implementation in the U.S. (Ryan and Schellhorn (2000))

- Increasing returns to scale for U.S. firms with up to US\$1 billion in assets (Cummins and $\mathrm{Zi}, 1998$ )

- Mostly evidence for economies of scope, more recently mixed evidence (Cummins et al., 2007) 
that independent agent distribution systems are more efficient than direct systems involving company representatives or employed agents. Against it, Berger et al. ${ }^{39}$ find for the U.S. that independent agent systems are less cost efficient, but equally profit efficient. On a more general level, Ward $^{57}$ finds for the U.K. that insurers focusing on one distribution system are more efficient than those employing more than one mode of distribution. Trigo Gamarra and Growitsch, ${ }^{58}$ in a study for German life insurance, finds that single line insurers are neither more cost nor more profit efficient than multichannel insurers.

\section{Financial and risk management, capital utilisation}

Cummins et al. ${ }^{59}$ were the first to explicitly investigate the relationship between risk management, financial intermediation, and economic efficiency. In their application to the U.S. property-liability industry, they analyse whether both activities contribute to efficiency through reducing costs of providing insurance. In order to show the contribution of risk management and financial intermediation to efficiency, they estimate shadow prices of these two activities. They find positive shadow prices of both activities and conclude that they significantly contribute to increasing efficiency. Brockett et al. ${ }^{60}$ argue that solvency is a primary concern for regulators of insurance companies; they thus use solvency scores determined by a neural network model as outputs in efficiency measurement, but they find that these scores only have limited impact on efficiency in the U.S. property-liability market. Cummins and Nini ${ }^{17}$ find for the same country and line of business, that large increases in capitalisation between 1989 and 1999 represent an inefficiency insofar as equity capital is significantly over-utilised.

\section{General level of efficiency and evolution over time}

This category contains a large number of studies that represent a first application of efficiency frontier methods to a country. Examples are Nigeria (see Barros and Obijiaku $^{61}$ ), Tunisia (see Chaffai and Ouertani ${ }^{62}$ ), Malaysia (see Mansor and Radam $^{63}$ ), or Australia (see Worthington and Hurley ${ }^{64}$ ). Given the broad range of countries and time horizons employed, findings regarding efficiency and productivity are mixed. However, nearly all studies note that there are significant levels of inefficiency with corresponding room for improvement. For example the Netherlands

\footnotetext{
${ }^{57}$ Ward (2002).

${ }^{58}$ Trigo Gamarra and Growitsch (2008).

${ }^{59}$ Cummins et al. (2006).

${ }^{60}$ Brockett et al. (2004a, b).

${ }^{61}$ Barros and Obijiaku (2007).

${ }^{62}$ Chaffai and Ouertani (2002).

${ }^{63}$ Mansor and Radam (2000).

${ }^{64}$ Worthington and Hurley (2002).
} 
with 75 per cent cost efficiency on average have significant improvement potential (see Bikker and van Leuvensteijn ${ }^{65}$ ). The same is true for China with average technical efficiency of 77 per cent in non-life and 70 per cent in life (see Yao et al. ${ }^{66}$ ), as well as Greece with average cost efficiency of 65 per cent (see Noulas et al. ${ }^{67}$ ).

\section{Intercountry comparisons}

The first cross-country comparison was conducted by Weiss. ${ }^{68}$ It covers the U.S., Germany, France, Switzerland, and Japan. She finds high productivity for the U.S. and Germany. Japan shows the weakest productivity growth for the period 1975-1987. Rai, ${ }^{10}$ in a broader cross-country study (11 OECD countries), concludes that firms in Finland and France have the highest efficiency and firms in the U.K. have the lowest. Donni and Fecher ${ }^{69}$ show for a sample of 15 OECD countries for the period 19831991 that average efficiency levels are relatively high, but vary across countries. Growth in productivity is observed for all countries, which is attributed to improvements in technical progress.

The introduction of the single European Union (EU) insurance license in 1994 raised concerns over international competitiveness among EU insurers. Consequently, there have been quite a few efficiency studies that focus on competition in the EU. For a sample of 450 companies from 15 European countries and for the period 1996-1999, Diacon et al. ${ }^{70}$ find striking international differences in average efficiency. According to their study, insurers doing long-term business in the U.K., Spain, Sweden, and Denmark have the highest levels of technical efficiency. However, U.K. insurers seem to have particularly low levels of scale and allocative efficiency compared to the other European countries in the sample. Interestingly, and in contrast to the literature finding increasing levels of efficiency over time, these authors find decreasing technical efficiency.

Boonyasai et al. $^{71}$ study efficiency and productivity in Asian insurance markets. Their results show increasing productivity in Korea and Philippines due to deregulation and liberalisation, but liberalisation had little effect on productivity in Taiwan and Thailand. The most recent stream of efficiency literature, however, again focuses on EU markets and includes Klumpes ${ }^{52}$ and Fenn et al. ${ }^{72}$ Fenn et al. ${ }^{72}$ find increasing returns to scale for the majority of EU insurers. The results indicate that mergers and acquisitions, facilitated by liberalised EU markets, have led to efficiency gains. Eling and Luhnen ${ }^{73}$ combine the AM Best U.S. and Non-U.S. database and

\footnotetext{
${ }^{65}$ Bikker and van Leuvensteijn (forthcoming).

66 Yao et al. (2007).

${ }^{67}$ Noulas et al. (2001).

${ }^{68}$ Weiss (1991 b).

${ }^{69}$ Donni and Fecher (1997).

${ }^{70}$ Diacon et al. (2002).

${ }^{71}$ Boonyasai et al. (2002).

${ }^{72}$ Fenn et al. (2008).

${ }^{73}$ Eling and Luhnen (2008).
} 
conduct a cross-country comparison of insurers from 36 countries, 12 of which have not previously been analysed in literature.

Overall, the empirical evidence is consistent in finding that efficiency in developed countries is higher than that in emerging markets and that technical progress has increased productivity and efficiency around the world. However, again the empirical findings are not unambiguous. An example is the U.K., where many studies have consistently indicated relatively low efficiency levels compared to other countries (around 60 per cent; see Rai ${ }^{10}$ Fenn et al. $;^{72}$ Vencappa et $a l .{ }^{74}$ ). Diacon, ${ }^{75}$ however, finds higher efficiency for the U.K. - 77 per cent, which is higher than that found for competing European countries in their study. Given that most efficiency research so far focuses on the U.S., significant need for research at the international level can be identified. With variations in market environments and cultural norms, we expect that future research will identify substantial differences in the results for the U.S. and for other insurance markets, for example, considering the effect of different organisational forms on efficiency or considering economies of scale and scope.

\section{Market structure}

Choi and Weiss ${ }^{76}$ analyse three hypotheses derived from the industrial organisation literature: (1) The structure-conduct-performance hypothesis predicts that increased market concentration leads to higher prices and profits through increased possibilities for collusion among firms; (2) the relative market power (RMP) hypothesis focuses on economic rents and predicts that firms with relatively large market shares will exercise their market power and charge higher prices; (3) the efficient structure (ES) hypothesis claims that more efficient firms charge lower prices than their competitors, allowing them to capture larger market shares as well as economic rents, leading to increased market concentration. Choi and Weiss ${ }^{12}$ confirm the ES hypothesis and suggest that regulators should be more concerned with efficiency rather than market power arising from industry consolidation. Results of Choi and Weiss ${ }^{77}$ support the RMP hypothesis, implying that insurers in competitive and non-stringently regulated U.S. states could profit from market power and charge higher unit prices. However, firms in those states have been found, on average, more cost efficient, and cost efficient insurers charge lower prices, earning smaller profits. A further contribution to the topic of market structure with a focus on the EU has been made by Fenn et al., ${ }^{72}$ finding that larger firms with high market shares tend to be less cost efficient.

\section{Mergers}

Kim and Grace $^{78}$ conduct a simulation analysis of efficiency gains from hypothetical horizontal mergers in the U.S. life insurance industry. Their results indicate that most

\footnotetext{
${ }^{74}$ Vencappa et al. (2008).

${ }^{75}$ Diacon (2001).

${ }^{76}$ Choi and Weiss $(2005,2008)$.

${ }^{77}$ Choi and Weiss (2008).

${ }^{78} \mathrm{Kim}$ and Grace (1995).
} 
mergers would improve cost efficiencies, with the exception of mergers between large firms. Two other U.S. studies (Cummins et al. ${ }^{79}$ for life insurance and Cummins and $\mathrm{Xie}^{80}$ for property-liability insurance) conclude that mergers are beneficial for the efficiency of acquiring and target firm. Klumpes ${ }^{52}$ tests the same hypothesis as Cummins et al. ${ }^{38}$ and Cummins and $\mathrm{Xie}^{80}$ for the European insurance market, and finds that acquiring firms are more likely to be efficient than non-acquiring firms. However, he finds no evidence that target firms achieve greater efficiency gains than non-target firms. Merger activity in the European insurance markets seems to be mainly driven by solvency objectives - that is, financially weak insurers are bought by financially sound companies - and less by value maximisation, as in the U.S.

\section{Methodology issues, comparing different techniques or assumptions}

A few studies primarily solve methodological issues or compare different techniques and assumptions over time. Cummins and $\mathrm{Zi}^{11}$ compare different frontier efficiency methods-DEA, DFA, FDH, SFA - and find that the efficiency results can differ significantly across these methods. Fuentes et al. ${ }^{22}$ introduce a parametric frontier approach for the application of the Malmquist index that has before that date only been used with non-parametric frontier approaches. Leverty and Grace ${ }^{43}$ compare the valueadded and intermediation approaches to efficiency measurement and find that these approaches are not consistent (see "Econometric approaches" and "Mathematical programming approaches" sections for more details on methodology and techniques).

\section{Organisational form, corporate governance issues}

A well-developed field of frontier efficiency analysis deals with the effect of organisational form on performance. The two principal hypotheses in this area are the expense preference hypothesis (see $\mathrm{Mester}^{81}$ ) and the managerial discretion hypothesis (see Mayers and $\mathrm{Smith}^{82}$ ). The expense preference hypothesis states that mutual insurers are less efficient than stock companies due to unresolved agency conflicts (e.g., higher perquisite consumption of mutual managers). The managerial discretion hypothesis claims that the two organisational forms use different technologies and that mutual companies are more efficient in lines of business with relatively low managerial discretion (see Cummins and Weiss ${ }^{1}$ ). ${ }^{83}$

The empirical evidence on these two hypotheses has been mixed. Most studies find that stock insurers are more efficient than mutuals, confirming the expense preference

\footnotetext{
${ }^{79}$ Cummins et al. (1999a).

${ }^{80}$ Cummins and Xie (2008).

${ }^{81}$ Mester (1991).

${ }^{82}$ Mayers and Smith (1988).

${ }^{83}$ The hypothesis that stocks and mutuals use different technologies is also called efficient structure hypothesis (Cummins et al., 2004; Wende et al., 2008), but this hypothesis is not related to the efficient structure hypothesis mentioned with the discussion of market structure in "Market structure" section.
} 
hypothesis (see, e.g., Cummins et al. ${ }^{38}$ and Erhemjamts and Leverty ${ }^{84}$ for the U.S. market; Diboky and $\mathrm{Ubl}^{3}$ for Germany). However, other studies have found mutuals more efficient than stocks. For example, Diacon et al. ${ }^{70}$ in a comparison of 15 European countries, find higher levels of technical efficiency for mutuals than for stocks. Also, Greene and Segal ${ }^{85}$ in an application to the U.S. life insurance industry, suggest that mutual companies are as cost efficient as stock companies. Other studies investigate efficiency improvements after demutualisation (see, e.g., Jeng et al. ${ }^{86}$ ) and compare the efficiency of firms after initial public offerings vs. that of private firms (see $\mathrm{Xie}^{87}$ ). Looking at corporate governance issues, a positive relation between cost efficiency and the size of the corporate board of directors was identified (see Hardwick et al. ${ }^{88}$ ).

\section{Regulation change}

The aim of deregulation in the financial services sector is to improve market efficiency and enhance consumer choice through more competition, but the empirical evidence is mixed. Rees et al. $^{89}$ find modest efficiency improvements from deregulation for the U.K. and German life insurance markets for the period from 1992 to 1994 . Hussels and $\mathrm{Ward}^{24}$ do not find clear evidence for a link between deregulation and efficiency for the same countries and line of business during the period 1991-2002. Mahlberg ${ }^{90}$ even finds decreasing efficiency for Germany considering life and property-liability insurance for the period of 1992-1996, but an increase in productivity. The results for Spain are different: Cummins and Rubio-Misas ${ }^{91}$ find clear evidence for total factor productivity growth for the period of 1989-1998, with consolidation reducing the number of firms in the market. Boonyasai et al. ${ }^{92}$ find evidence for productivity increases in Korea and the Philippines due to deregulation. Considering the U.S., Ryan and Schellhorn ${ }^{93}$ find unchanged efficiency levels from the start of the 1990s to the middle of that decade, a period during which risk-based capital (RBC) requirements became effective. Recently, Yuan and Phillips ${ }^{94}$ find evidence for cost scope diseconomies and revenue scope economies for the integrated banking and insurance sectors after changes due to the Gramm-Leach-Bliley Act of 1999.

\section{Scale and scope economies}

Scale economies have been extensively researched in the context of consolidation and the justification of mergers (see Cummins and Weiss ${ }^{1}$ ). Although detailed results vary

\footnotetext{
${ }^{84}$ Erhemjamts and Leverty (2007).

${ }^{85}$ Greene and Segal (2004).

${ }^{86}$ Jeng et al. (2007).

${ }^{87}$ Xie (2008).

${ }^{88}$ Hardwick et al. (2004).

${ }^{89}$ Rees et al. (1999).

${ }^{90}$ Mahlberg (2000).

${ }^{91}$ Cummins and Rubio-Misas (2006).

92 Boonyasai et al. (2002).

93 Ryan and Schellhorn (2000).

${ }^{94}$ Yuan and Phillips (2008).
} 
across studies, depending on countries, methods, and time horizons employed, many contributions have found, on average, evidence for increasing returns to scale (see, e.g., Fecher et al. ${ }^{95}$ for U.K.; Hardwick ${ }^{96}$ for Ireland; Hwang and Gao ${ }^{97}$ for China; and Qiu and Chen ${ }^{98}$ for France). However, the differentiation between size clusters must be considered to achieve more specific results. For example, Yuengert ${ }^{47}$ finds increasing returns to scale for U.S. life insurance firms with up to US\$15 billion in assets and CRS for bigger firms. In contrast, Cummins and $\mathrm{Zi},{ }^{11}$ for the same market, find increasing returns to scale for firms having up to US\$1 billion in assets, and decreasing returns to scale for all others except for a few firms with CRS.

The two main hypotheses regarding economies of scope are the conglomeration hypothesis, which holds that operating a diversity of business can add value by exploiting cost and revenue scope economies, and the strategic focus hypothesis, which holds that firms can best add value by focusing on core businesses (see Cummins et $a l .{ }^{99}$ ). Considering U.S. life insurers, Meador et al. ${ }^{100}$ find that diversification across multiple insurance and investment product lines resulted in greater efficiency which is in line with the conglomeration hypothesis. Fuentes et al. ${ }^{101}$ also find evidence for economies of scope, in their case for Spanish life and non-life insurers. Berger et al. ${ }^{102}$ show for the U.S. that profit scope economies are more likely to be realised by larger firms. In contrast to all these authors, Cummins et al. ${ }^{99}$ use cross-frontier analysis and find mixed results with regard to scope economies.

\section{Conclusion and implications for future research}

In recent years academics, practitioners and policy-makers have spent significant attention to frontier efficiency techniques in the insurance industry. The purpose of this paper was to provide an overview of this rapidly growing field of research. We analyse 95 studies on efficiency measurement in the insurance sector, provide a systematisation of different applications and highlight recent developments. The paper serves as a comprehensive overview of relevance not only to researchers interested in frontier efficiency studies, but also to regulators and managers for more practical reasons.

DEA is the most frequently applied method in studies conducting frontier efficiency analysis in insurance - 55 out of 95 papers apply DEA. In recent years, there have been a number of proposals for improving both econometric and mathematical programming approaches. Proposals include, for example, the development of more appropriate functional forms for the econometric approaches or the introduction of bootstrapping procedures for the mathematical programming approaches. With

\footnotetext{
${ }^{95}$ Fecher et al. (1991).

96 Hardwick (1997).

${ }^{97}$ Hwang and Gao (2005).

${ }^{98}$ Qiu and Chen (2006).

${ }^{99}$ Cummins et al. (2007).

100 Meador et al. (2000).

101 Fuentes et al. (2005).

102 Berger et al. (2000).
} 
regard to the choice of input factors, there seems to be widespread agreement among researchers: 61 out of 95 studies use at least labour and capital as inputs and most of them also add a third category, usually business services. With regard to output measurement, most studies employ the value-added approach (80 out of 95). However, there is some controversy over whether premiums or claims are the better proxy for value added. In recent years, there has been an expansion of frontier efficiency measurement in insurance to new fields of application, such as market structure and risk management. Also, the geographic scope has been rapidly growing, moving from a previously U.S.-focused view to a broad set of countries around the world.

The large number of studies is indicative of increasing interest in the international competitiveness and efficiency of insurance companies and our survey has brought to light a number of opportunities for future research. First of all, significant research potential can be identified at the international level. Most of the existing cross-country comparisons are either focused on Europe- such as Fenn et al. ${ }^{72}$ and Diacon et al. ${ }^{70}$ - or consider relatively small datasets - such as Rai, ${ }^{10}$ which covers only 106 companies in 11 countries. In this context, the relatively new research topics of market structure (see, e.g., Choi and Weiss ${ }^{77}$ ) and risk management (see, e.g., Cummins et $a l .{ }^{59}$ ) need to be analysed for a larger sample of countries. This would allow us to move away from the U.S. focus of the few studies that have been published to date. Another research idea in this context would be to use cross-frontier analysis to compare the production technology in different countries.

For studies on risk and financial management, a link to the discussion regarding the implementation of new RBC standards for insurers, such as Solvency II (see, e.g., Eling et al. ${ }^{103}$ ), would be of interest. In this case, the possible impact of different solvency proposals on efficiency could be evaluated. Given that corporate governance is often considered as a potential cause of the recent financial market crisis, the link between corporate governance and efficiency needs closer consideration.

A widening of the research arena beyond the U.S. is also needed when it comes to analysis of mergers and efficiency. For example, all studies on this topic except for one (Klumpes ${ }^{52}$ ) are U.S.-focused. Regarding the coverage of different lines of business, it becomes obvious that most studies have been implemented at relatively high levels of aggregation. Academic contributions on efficiency performance of sublines of business - for example, auto insurance, as done by Choi and Weiss ${ }^{77}$ or homeowner insurance-would be of special interest for countries where appropriate data are available.

Most efficiency studies only interpret the efficiency numbers, but the analysis provides a lot more interesting information such as the marginal rate of substitution (if the shadow prices of two inputs are compared), the marginal productivity (if the shadow prices of one input and one output are compared), and the marginal rate of transformation (if the shadow prices of two outputs are compared). The shadow prices, however, have not yet been in focus of much of the literature. Considering stochastic frontier analysis, an important contribution would be to find which

103 Eling et al. (2007). 
functional form best fits empirical cost or profit functions, again with possible differences between lines of businesses and countries. Furthermore, efficiency can be measured for each decision-making unit in a company, that is, for each business unit or line of business; the link between capital allocation in insurance companies that is controversially discussed in recent literature (Myers and Read; ${ }^{104}$ Gründl and Schmeiser ${ }^{105}$ ) and efficiency could thus be a fruitful area of future research. Overall, frontier efficiency measurement has been one of the most rapidly growing streams of insurance literature in the last years and so it will be in the future.

\section{References}

Aigner, D.J., Lovell, C.A.K. and Schmidt, P. (1977) 'Formulation and estimation of stochastic frontier production function models', Journal of Econometrics 6(1): 21-37.

Badunenko, O., Grechanyuk, B. and Talavera, O. (2006) Development under regulation: The way of the Ukrainian insurance market, discussion papers of DIW Berlin 644, DIW Berlin, German Institute for Economic Research.

Banker, R.D. (1993) 'Maximum likelihood, consistency and data envelopment analysis: A statistical foundation', Management Science 39(10): 1265-1273.

Barros, C.P. and Obijiaku, E.L. (2007) Technical efficiency of Nigerian insurance companies, working papers no. 18, Department of Economics, Institute for Economics and Business Administration (ISEG), Technical University of Lisbon.

Barros, C.P., Barroso, N. and Borges, M.R. (2005) 'Evaluating the efficiency and productivity of insurance companies with a Malmquist Index: A case study for Portugal', The Geneva Papers on Risk and Insurance-Issues and Practice 30(2): 244-267.

Berger, A.N. and Humphrey, D.B. (1997) 'Efficiency of financial institutions: International survey and directions for future research', European Journal of Operational Research 98(2): 175-212.

Berger, A.N., Cummins, J.D. and Weiss, M.A. (1997) 'The coexistence of multiple distribution systems for financial services: The case of property-liability insurance', Journal of Business 70(4): 515-546.

Berger, A.N., Cummins, J.D., Weiss, M.A. and Zi, H. (2000) 'Conglomeration versus strategic focus: Evidence from the insurance industry', Journal of Financial Intermediation 9(4): 323-362.

Bernstein, J.I. (1999) 'Total factor productivity growth in the Canadian life insurance industry: 1979-1989', Canadian Journal of Economics 32(2): 500-517.

Bikker, J.A. and van Leuvensteijn, M. (forthcoming) 'Competition and efficiency in the Dutch life insurance industry', Applied Economics 40(16): 2063-2084.

Boonyasai, T., Grace, M.F. and Skipper Jr., H.D. (2002) The effect of liberalization and deregulation on life insurer efficiency, working paper no. 02-2, Center for Risk Management and Insurance Research, Georgia State University, Atlanta.

Brockett, P.L., Cooper, W.W., Golden, L.L., Rousseau, J.J. and Wang, Y. (1998) 'DEA evaluations of the efficiency of organizational forms and distribution systems in the US property and liability insurance industry', International Journal of Systems Science 29(11): 1235-1247.

Brockett, P.L., Cooper, W.W., Golden, L.L., Rousseau, J.J. and Wang, Y. (2004a) 'Evaluating solvency versus efficiency performance and different forms of organization and marketing in US property-liability insurance companies', European Journal of Operational Research 154(2): 492-514.

Brockett, P.L., Chang, R.C., Rousseau, J.J., Semple, J.H. and Yang, C. (2004b) 'A comparison of HMO efficiencies as a function of provider autonomy', Journal of Risk and Insurance 71(1): 1-19.

Brockett, P.L., Cooper, W.W., Golden, L.L., Rousseau, J.J. and Wang, Y. (2005) 'Financial intermediary versus production approach to efficiency of marketing distribution systems and organizational structure of insurance companies', Journal of Risk and Insurance 72(3): 393-412.

\footnotetext{
104 Myers and Read (2001).

105 Gründl and Schmeiser (2007).
} 
Martin Eling and Michael Luhnen

Efficiency in the Insurance Industry

Carr, R.M., Cummins, J.D. and Regan, L. (1999) 'Efficiency and competitiveness in the US life insurance industry: Corporate, product, and distribution strategies', in J.D. Cummins and A.M. Santomero (eds.) Changes in the Life Insurance Industry: Efficiency, Technology and Risk Management, Boston, MA: Kluwer Academic Publishers.

Caves, D.W., Christensen, L.R. and Tretheway, M.W. (1980) 'Flexible cost functions for multiproduct firms', Review of Economics and Statistics 62(3): 477-482.

Chaffai, M.E. and Ouertani, M.N. (2002) Technical efficiency in the Tunisian insurance industry: A comparison of parametric and non parametric time variant models, working paper, Research Unit on Production Econometrics, Sfax University, Sfax.

Choi, P.B. and Weiss, M.A. (2005) 'An empirical investigation of market structure, efficiency, and performance in property-liability insurance', Journal of Risk and Insurance 72(4): 635-673.

Choi, P.B. and Weiss, M.A. (2008) 'State regulation and the structure, conduct, efficiency and performance of US auto insurers', Journal of Banking and Finance 32(1): 134-156.

Cooper, W.W., Seiford, L.M. and Tone, K. (2007) Data Envelopment Analysis: A Comprehensive Text with Models, Applications, References and DEA-solver Software, Boston, MA: Springer.

Cummins, J.D. (1999) 'Efficiency in the US life insurance industry: Are insurers minimizing costs and maximizing revenues?', in J.D. Cummins and A.M. Santomero (eds.) Changes in the Life Insurance Industry: Efficiency, Technology and Risk Management, Boston, MA: Kluwer Academic Publishers.

Cummins, J.D. and Nini, G.P. (2002) 'Optimal capital utilization by financial firms: Evidence from the property-liability insurance industry', Journal of Financial Services Research 21(1-2): 15-53.

Cummins, J.D. and Rubio-Misas, M. (2006) 'Deregulation, consolidation, and efficiency: Evidence from the Spanish insurance industry', Journal of Money, Credit, and Banking 38(2): 323-355.

Cummins, J.D. and Weiss, M.A. (1993) 'Measuring cost efficiency in the property-liability insurance industry', Journal of Banking and Finance 17(2-3): 463-481.

Cummins, J.D. and Weiss, M.A. (2000) 'Analyzing firm performance in the insurance industry using frontier efficiency methods', in G. Dionne (ed.) Handbook of Insurance Economics, Boston, MA: Kluwer Academic Publishers.

Cummins, J.D. and Xie, X. (2008) 'Mergers and acquisitions in the US property-liability insurance industry: Productivity and efficiency effects', Journal of Banking and Finance 32(1): 30-55.

Cummins, J.D. and Zi, H. (1998) 'Comparison of frontier efficiency methods: An application to the U.S. life insurance industry', Journal of Productivity Analysis 10(2): 131-152.

Cummins, J.D., Rubio-Misas, M. and Zi, H. (2004) 'The effect of organizational structure on efficiency: Evidence from the Spanish insurance industry', Journal of Banking and Finance 28(12): 3113-3150.

Cummins, J.D., Tennyson, S. and Weiss, M.A. (1999a) 'Consolidation and efficiency in the U.S. life insurance industry', Journal of Banking and Finance 23(2-4): 325-357.

Cummins, J.D., Turchetti, G. and Weiss, M.A. (1996) Productivity and technical efficiency in the Italian insurance industry, working paper, Wharton Financial Institutions Center, University of Pennsylvania, Pennsylvania.

Cummins, J.D., Weiss, M.A. and Zi, H. (1999b) 'Organizational form and efficiency: The coexistence of stock and mutual property-liability insurers', Management Science 45(9): 1254-1269.

Cummins, J.D., Weiss, M.A. and Zi, H. (2007) Economics of scope in financial services: A DEA bootstrapping analysis of the US insurance industry, Working Paper, The Wharton School, Philadelphia, Pennsylvania.

Cummins, J.D., Dionne, G., Gagné, R. and Nouira, A. (2006) Efficiency of insurance firms with endogenous risk management and financial intermediation activities, Working Paper.

Davutyan, N. and Klumpes, P.J.M. (2008) Consolidation and efficiency in the major European insurance markets: A non discretionary inputs approach, Working Paper.

Delhausse, B., Fecher, F. and Pestieau, P. (1995) 'Measuring productive performance in the non-life insurance industry: The case of French and Belgian markets', Tijdschrift voor Economie en Management 40(1): 47-69.

Diacon, S.R. (2001) The efficiency of UK general insurance companies, working paper, Centre for Risk \& Insurance Studies, University of Nottingham.

Diacon, S.R., Starkey, K. and O'Brien, C. (2002) 'Size and efficiency in European long-term insurance companies: An international comparison', The Geneva Papers on Risk and Insurance-Issues and Practice 27(3): 444-466. 
Diboky, F. and Ubl, E. (2007) Ownership and efficiency in the German life insurance market: $A$ DEA bootstrap approach, working paper, University of Vienna.

Donni, O. and Fecher, F. (1997) 'Efficiency and productivity of the insurance industry in the OECD countries', The Geneva Papers on Risk and Insurance-Issues and Practice 22(4): 523-535.

Donni, O. and Hamende, V. (1993) 'Performance des Sociétés Belges D’Assurance-Comparaison des formes institutionelles', Annals of Public and Cooperative Economics 64(3): 419-438, Université de Liège.

Eling, M. and Luhnen, M. (2008) Efficiency in the international insurance industry: A cross-country comparison, working paper, University of St. Gallen.

Eling, M., Schmeiser, H. and Schmit, J.T. (2007) 'The Solvency II process: Overview and critical analysis', Risk Management and Insurance Review 10(1): 69-85.

Ennsfellner, K.C., Lewis, D. and Anderson, R.I. (2004) 'Production efficiency in the Austrian insurance industry: A Bayesian examination', Journal of Risk and Insurance 71(1): 135-159.

Erhemjamts, O. and Leverty, J.T. (2007) The demise of the mutual organizational form: An investigation of the life insurance industry, Working Paper.

Fecher, F., Perelman, S. and Pestieau, P. (1991) 'Scale economics and performance in the French insurance industry', The Geneva Papers on Risk and Insurance - Issues and Practice 16(3): 315-326.

Fecher, F., Kessler, D., Perelman, S. and Pestieau, P. (1993) 'Productive performance of the French insurance industry', Journal of Productivity Analysis 4(1-2): 77-93.

Fenn, P., Vencappa, D., Diacon, S., Klumpes, P. and O'Brien, C. (2008) 'Market structure and the efficiency of European insurance companies: A stochastic frontier analysis', Journal of Banking and Finance 32(1): 86-100.

Fuentes, H., Grifell-Tatjé, E. and Perelman, S. (2001) 'A parametric distance function approach for Malmquist productivity index estimation', Journal of Productivity Analysis 15(2): 79-94.

Fuentes, H., Grifell-Tatjé, E. and Perelman, S. (2005) Product specialization, efficiency and productivity change in the Spanish insurance industry, working paper, Universite de Liège.

Fukuyama, H. (1997) 'Investigating productive efficiency and productivity changes of Japanese life insurance companies', Pacific-Basin Finance Journal 5(4): 481-509.

Fukuyama, H. and Weber, W.L. (2001) 'Efficiency and productivity change of non-life insurance companies in Japan', Pacific Economic Review 6(1): 129-146.

Gallant, A.R. (1982) 'Unbiased determination of production technologies', Journal of Econometrics 20(2): $285-323$.

Gardner, L.A. and Grace, M.F. (1993) 'X-efficiency in the US life insurance industry', Journal of Banking and Finance 17(2-3): 497-510.

Grace, M.F. and Timme, S.G. (1992) 'An examination of cost economies in the United States life insurance industry', Journal of Risk and Insurance 59(1): 72-103.

Greene, W.H. and Segal, D. (2004) 'Profitability and efficiency in the US life insurance industry', Journal of Productivity Analysis 21(3): 229-247.

Grosskopf, S. (1993) 'Efficiency and productivity', in H.O. Fried, C.A.K. Lovell and S.S. Schmidt (eds.) The Measurement of Productive Efficiency: Techniques and Applications, Oxford: Oxford University Press.

Gründl, H. and Schmeiser, H. (2007) 'Capital allocation for insurance companies-what good is it?' Journal of Risk and Insurance 74(3): 301-317.

Hancock, D. (1985) 'The financial firm: Production with monetary and nonmonetary goods', Journal of Political Economy 93(5): 859-880.

Hao, J.C.J. (2007) 'Efficiency test on Taiwan's life insurance industry-using x-efficiency approach', Information and Management Sciences 18(1): 37-48.

Hao, J.C.J. and Chou, L.-Y. (2005) 'The estimation of efficiency for life insurance industry: The case in Taiwan', Journal of Asian Economics 16(5): 847-860.

Hardwick, P. (1997) 'Measuring cost inefficiency in the UK life insurance industry', Applied Financial Economics 7(1): 37-44.

Hardwick, P., Adams, M. and Zou, H. (2004) Corporate governance and cost efficiency in the United Kingdom life insurance industry, Working Paper.

Hirao, Y. and Inoue, T. (2004) 'On the cost structure of the Japanese property-casualty insurance industry', Journal of Risk and Insurance 71(3): 501-530.

Huang, W. (2007) Efficiency in the China insurance industry: 1999-2004, Working Paper. 
Huang, C. and Liu, J. (1994) 'Estimation of a non-neutral stochastic frontier production function', Journal of Productivity Analysis 5(2): 171-180.

Hussels, S. and Ward, D.R. (2006) The impact of deregulation on the German and UK life insurance markets: An analysis of efficiency and productivity between 1991-2002, Working Paper, Cranfield Management Research Paper Series (4).

Hwang, S.N. and Kao, C. (2008a) 'Using two-stage DEA to measure managerial efficiency change of non-life insurance companies in Taiwan', International Journal of Management and Decision Making 9(4): $377-401$.

Hwang, S.N. and Kao, C. (2008b) 'Efficiency decomposition in two-stage data envelopment analysis: An application to non-life insurance companies in Taiwan', European Journal of Operational Research 185(1): 418-429.

Hwang, T. and Gao, S.S. (2005) 'An empirical study of cost efficiency in the Irish life insurance industry', International Journal of Accounting, Auditing and Performance Evaluation 2(3): 264-280.

Jeng, V. and Lai, G.C. (2005) 'Ownership structure, agency costs, specialization, and efficiency: Analysis of Keiretsu and independent insurers in the Japanese nonlife insurance industry', Journal of Risk and Insurance 72(1): 105-158.

Jeng, V., Lai, G.C. and McNamara, M.J. (2007) 'Efficiency and demutualization: Evidence from the U.S. life insurance industry in the 1980s and 1990s', Journal of Risk and Insurance 74(3): 683-711.

Kessner, K. (2001a) 'Ein Effizienzvergleich deutscher und britischer Lebensversicherungen', In: Markttransparenz und Produktionseffizienz in der deutschen Lebensversicherung. Dissertation, LudwigMaximilians-Universität München.

Kessner, K. (2001b) 'Skaleneffizienz und Produktivitätswachstum in der deutschen Lebensversicherung', In: Markttransparenz und Produktionseffizienz in der deutschen Lebensversicherung. Dissertation, Ludwig-Maximilians-Universität München.

Kessner, K. and Polborn, M. (1999) 'Eine Effizienzanalyse der deutschen Lebensversicherer-die Best Practice Methode', Zeitschrift für die gesamte Versicherungswissenschaft 88(2-3): 469-488.

Kim, H. and Grace, M.F. (1995) Potential ex post efficiency gains of insurance company mergers, working paper, Center for RMI Research 95-4, College of Business Administration, Georgia State University, Atlanta.

Klumpes, P.J.M. (2004) 'Performance benchmarking in financial services: Evidence from the UK life insurance industry', Journal of Business 77(2): 257-274.

Klumpes, P.J.M. (2007) Consolidation and efficiency in the major European insurance markets, Working Paper, Imperial College, London.

Kumbhakar, S.C. and Lovell, C.A.K. (2000) Stochastic Frontier Analysis, New York: Cambridge University Press.

Leverty, T.J. and Grace, M.F. (2008) Issues in measuring the efficiency of property-liability insurers, Working Paper.

Leverty, T., Lin, Y. and Zhou, H. (2004) Firm performance in the Chinese insurance industry, Wharton Working Paper.

Luhnen, M. (2008) Determinants of efficiency and productivity in German property-liability insurance: Evidence for 1995-2006, Working Paper, University of St. Gallen.

Mahlberg, B. (1999) 'Effizienzmessung österreichischer und deutscher Versicherungen-Ein Vergleich', Wirtschaftspolitische Blätter 46(4): 400-406.

Mahlberg, B. (2000) 'Technischer Fortschritt und Produktivitätsveränderungen in der deutschen Versicherungswirtschaft', Jahrbücher für Nationalökonomik und Statistik 220(5): 565-591.

Mahlberg, B. and Url, T. (2000) The transition to the single market in the German insurance industry, Working Paper, Austrian Institute of Economic Research.

Mahlberg, B. and Url, T. (2003) 'Effects of the single market on the Austrian insurance industry', Empirical Economics 28(4): 813-838.

Mansor, S.A. and Radam, A. (2000) 'Productivity and efficiency performance of the Malaysian life insurance industry', Jurnal Ekonomi Malaysia 34(1): 93-105.

Mayers, D. and Smith, C.W. (1988) 'Ownership structure across lines of property-casualty insurance', Journal of Law and Economics 31(2): 351-378.

Meador, J.W., Ryan Jr., H.E. and Schellhorn, C.D. (2000) Product focus versus diversification: Estimates of $x$-efficiency for the US life insurance industry, Working Paper, Wharton Financial Institutions Center, University of Pennsylvania. 
Mester, L.J. (1991) 'Agency costs among savings and loans', Journal of Financial Intermediation 1(3): 257-278.

Morrison, C.J. and Berndt, E.R. (1982) 'Short-run labor productivity in a dynamic model', Journal of Econometrics 16(3): 339-365.

Myers, S.C. and Read Jr., J.A. (2001) 'Capital allocation for insurance companies', Journal of Risk and Insurance 68(4): 545-580.

Noulas, A.G., Hatzigayios, T., Lazaridis, J. and Lyroudi, K. (2001) 'Non-parametric production frontier approach to the study of efficiency of non-life insurance companies in Greece', Journal of Financial Management and Analysis 14(1): 19-26.

Pulley, L.B. and Braunstein, Y. (1992) 'A composite cost function for multiproduct firms with an application to economies of scope in banking', Review of Economics and Statistics 74(2): 221-230.

Qiu, S. and Chen, B. (2006) Efficiencies of life insurers in China-An application of data envelopment analysis, working paper.

Rai, A. (1996) 'Cost efficiency of international insurance firms', Journal of Financial Services Research 10(3): $213-233$

Rees, R., Kessner, E., Klemperer, P. and Matutes, C. (1999) 'Regulation and efficiency in European insurance markets', Economic Policy 14(29): 363-397.

Ryan Jr., H.E. and Schellhorn, C.D. (2000) 'Life insurer cost efficiency before and after implementation of the NAIC risk-based capital standards', Journal of Insurance Regulation 18(3): 362-384.

Simar, L. and Wilson, P.W. (1998) 'Sensitivity analysis of efficiency scores: How to bootstrap in nonparametric frontier models', Management Science 44(1): 49-61.

Simar, L. and Wilson, P.W. (2007) 'Estimation and inference in two-stage, semi-parametric models of production processes', Journal of Econometrics 136(1): 31-64.

Toivanen, O. (1997) 'Economies of scale and scope in the Finnish non-life insurance industry', Journal of Banking and Finance 21(6): 759-779.

Tone, K. and Sahoo, B.K. (2005) 'Evaluating cost efficiency and returns to scale in the life insurance corporation of India using data envelopment analysis', Socio-Economic Planning Sciences 39(4): 261-285.

Trigo Gamarra, L. (2008) The effects of liberalization and deregulation on the performance of financial institutions: The case of the German life insurance market, Working Paper, University of Rostock.

Trigo Gamarra, L. and Growitsch, C. (2008) Single-versus multi-channel distribution strategies in the German life insurance market: A cost and profit efficiency analysis, Thünen-Series of Applied Economic Theory Working Paper no. 81, University of Rostock.

Turchetti, G. and Daraio, C. (2004) 'How deregulation shapes market structure and industry efficiency: The case of the Italian motor insurance industry', The Geneva Papers on Risk and Insurance-Issues and Practice 29(2): 202-218.

Van den Broeck, J., Koop, G., Osiewalski, J. and Steel, M.F.J. (1994) 'Stochastic frontier models: A Bayesian perspective', Journal of Econometrics 61(2): 273-303.

Vencappa, D., Fenn, P. and Diacon, S. (2008) Parametric decomposition of total factor productivity growth in the European insurance industry: Evidence from life and non-life companies, Working Paper.

Ward, D. (2002) 'The costs of distribution in the UK life insurance market', Applied Economics 34(15): 1959-1968.

Weiss, M.A. (1986) 'Analysis of productivity at the firm level: An application to life insurers', Journal of Risk and Insurance 53(1): 49-84.

Weiss, M.A. (1991a) 'Efficiency in the property-liability insurance industry', Journal of Risk and Insurance 58(3): 452-479.

Weiss, M.A. (1991b) 'International P/L insurance output, input, and productivity comparisons', Geneva Papers on Risk and Insurance Theory 16(2): 179-200.

Wende, S., Berry-Stölzle, T.R. and Lai, G.L. (2008) The effect of regulation on comparative advantages of different organizational forms: Evidence from the German property-liability insurance industry, Working Paper, University of Cologne.

Worthington, A.C. and Hurley, E.V. (2002) 'Cost efficiency in Australian general insurers: A non-parametric approach', British Accounting Review 34(1): 89-108.

Wu, D., Yang, Z., Vela, S. and Liang, L. (2007) 'Simultaneous analysis of production and investment performance of Canadian life and health insurance companies using data envelopment analysis', Computers \& Operations Research 34(1): 180-198. 
Xie, X. (2008) Are publicly held firms less efficient? Evidence from the U.S. property-liability insurance industry, Working Paper.

Yang, Z. (2006) 'A two-stage DEA model to evaluate the overall performance of Canadian life and health insurance companies and computer', Mathematical and Computer Modelling 43(7-8): 910-919.

Yao, S., Han, Z. and Feng, G. (2007) 'On technical efficiency of China's insurance industry after WTO accession', China Economic Review 18(1): 66-86.

Yuan, Y. and Phillips, R.D. (2008) Financial integration and scope efficiency in U.S. financial services post Gramm-Leach-Bliley, Working Paper.

Yuengert, A.M. (1993) 'The measurement of efficiency in life insurance: estimates of a mixed normal-gamma error model', Journal of Banking and Finance 17(2-3): 483-496.

Zanghieri, P. (2008) Efficiency of European insurance companies: Do local factors matter?, Working Paper, Association of Italian Insurers, Rome. 


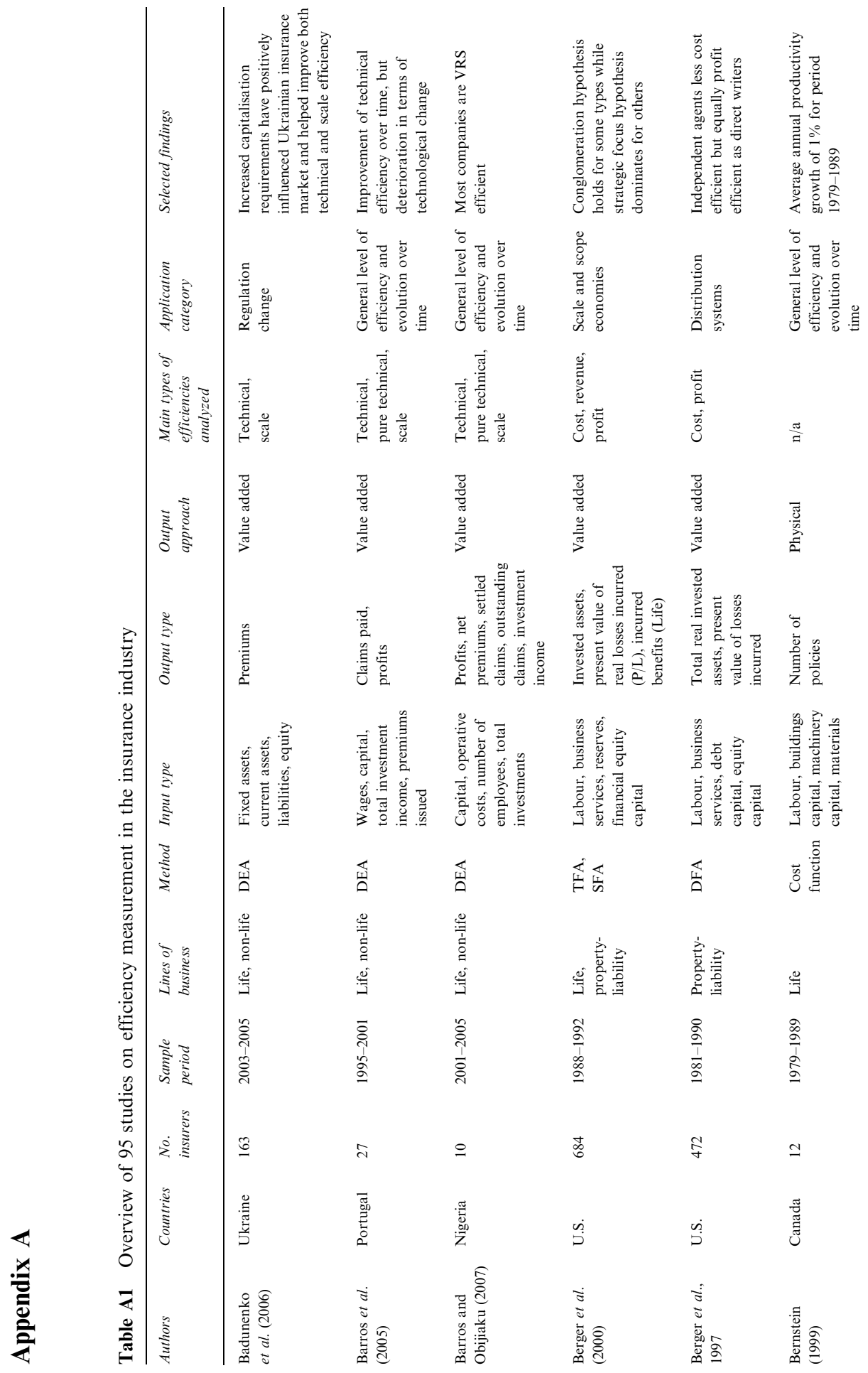



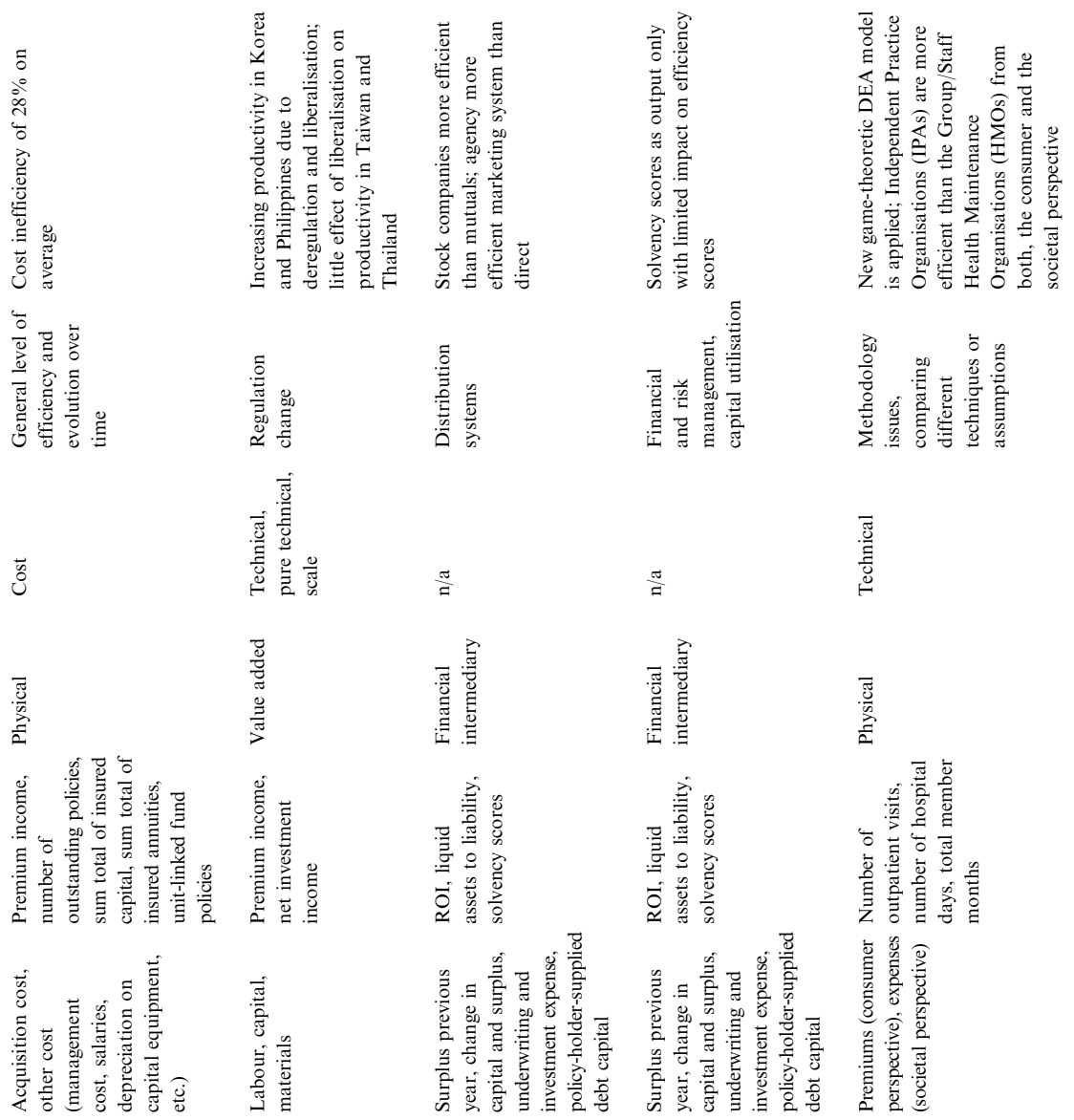

在

画

苗

푬

똠

:

商

竞:

플

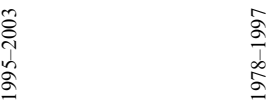

$\stackrel{9}{\stackrel{8}{9}}$

$\stackrel{\circ}{\circ}$

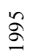

学

$\stackrel{\circ}{\frac{9}{9}}$

꼰

苋

$\infty$

章

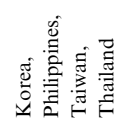

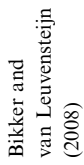

:

$\stackrel{\omega}{5}$

$\stackrel{s}{5}$

$\stackrel{s}{s}$

总

㠃 


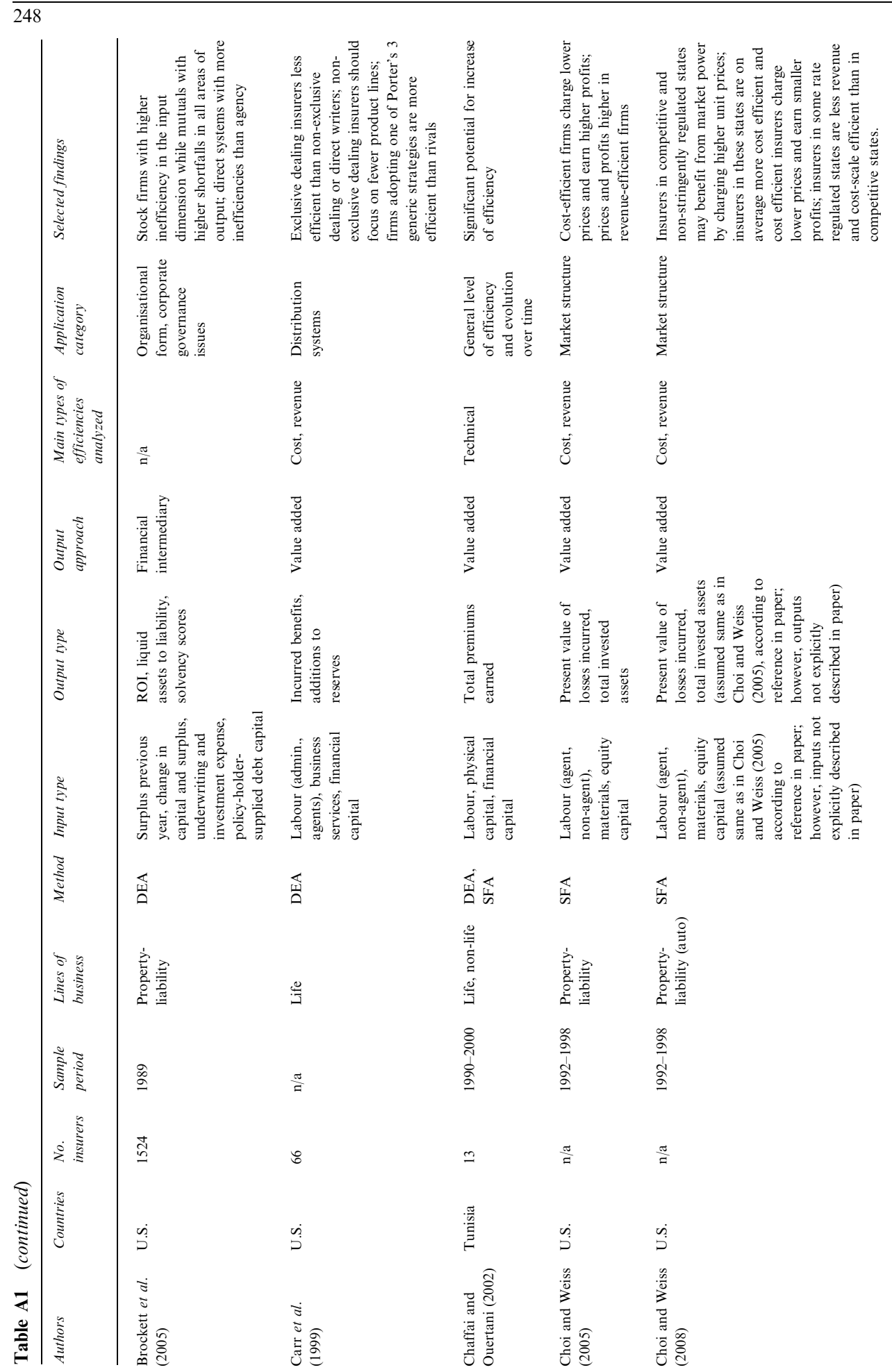



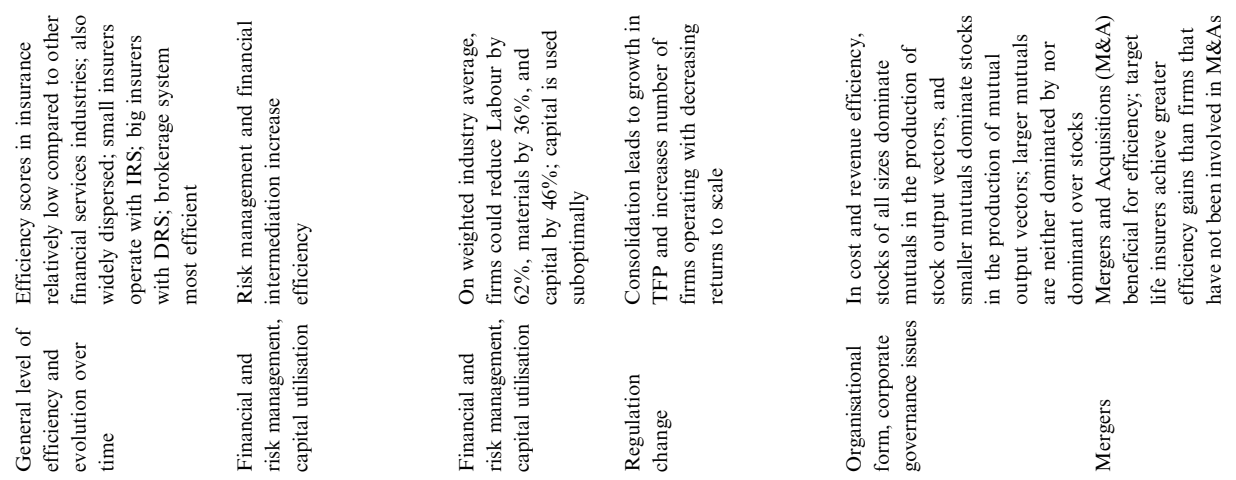

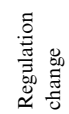

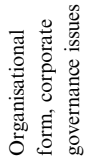

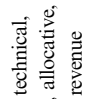

言尊营

预导递

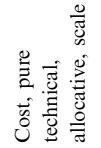

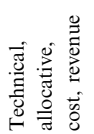

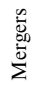

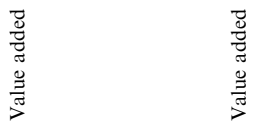

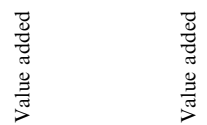

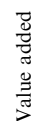

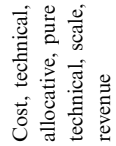

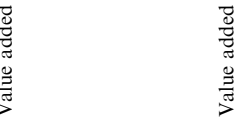

竞势

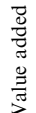

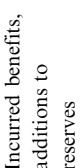

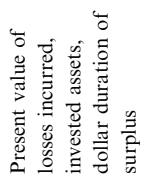

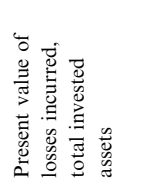

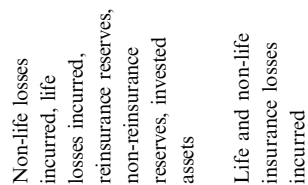

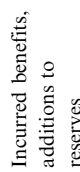

音总焉

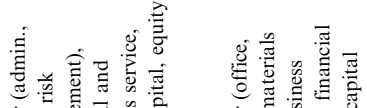

离泀总

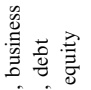

Iñ

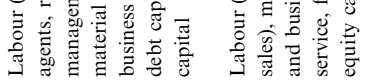

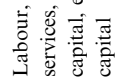

言总焉焉

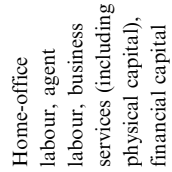

嘼

路

푬

菌

푬

苗

言部

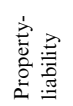

$\frac{0}{1}$

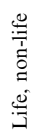

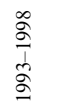

$\frac{\infty}{\circ}$

$\stackrel{\varrho}{\Xi}$

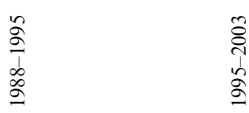

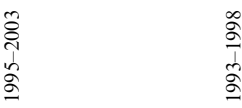

5
$\stackrel{5}{\sigma}$
$\stackrel{5}{\circ}$

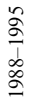

\&

$\stackrel{\circ}{8}$

:

$\frac{\infty}{m}$

兴

:
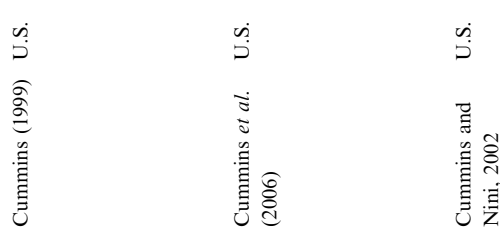

帚

衰

$\stackrel{s}{s}$

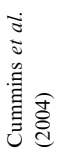

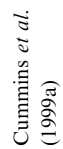




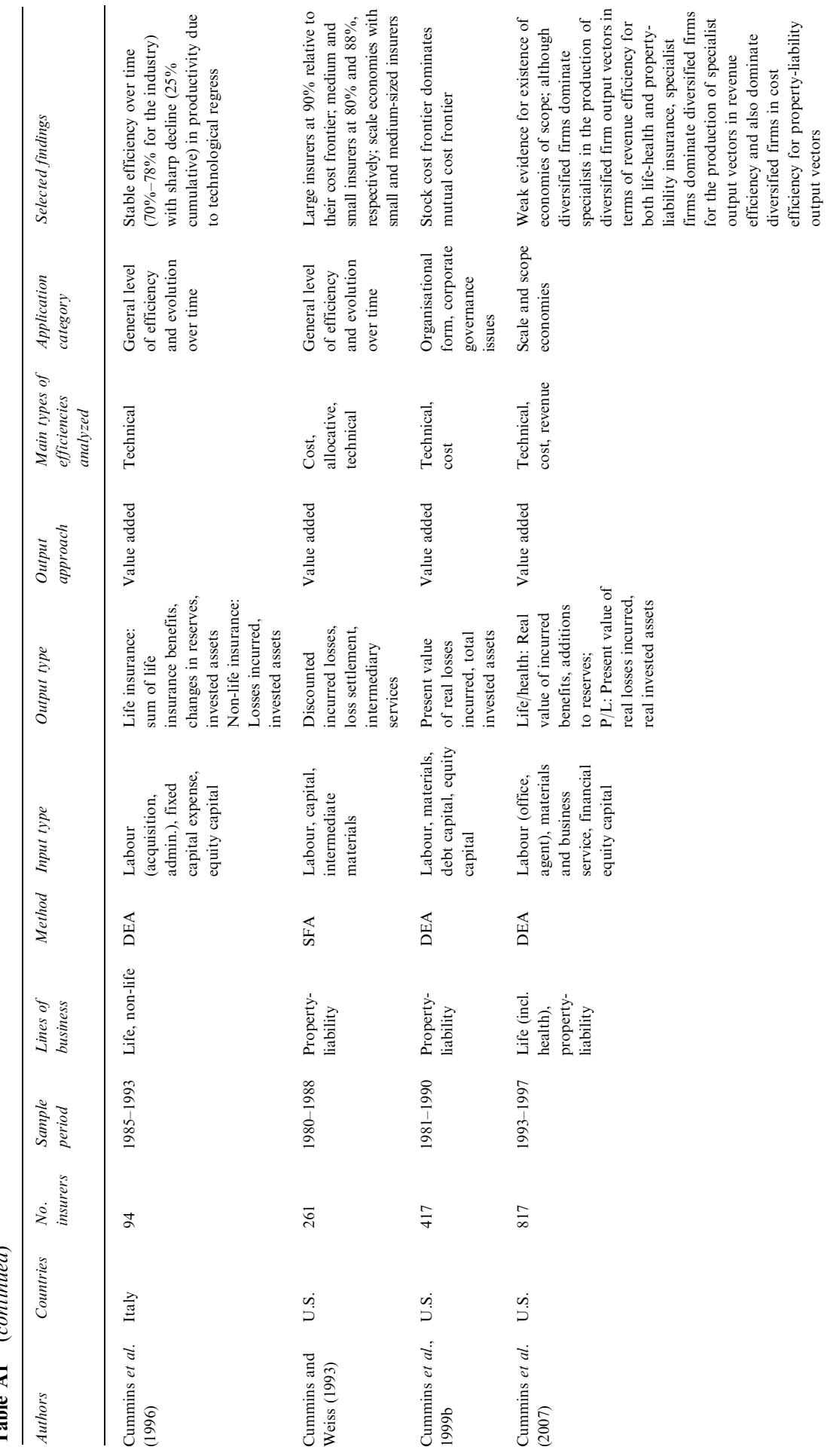


$\sum_{\substack{\Delta \\ \grave{0}}}^{\infty}$

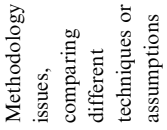

焉产产尊

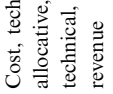

$\frac{\pi}{0}$
$\frac{0}{\pi}$
$\frac{\pi}{\pi}$
$\frac{\pi}{\pi}$

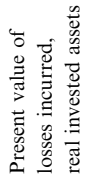

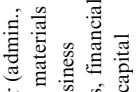

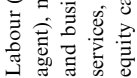

娦

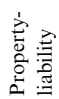

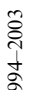

ถุ

$\dot{s}$

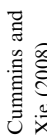

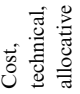

$\frac{8}{0}$
$\frac{\pi}{\pi}$
$\frac{0}{\pi}$
$\frac{0}{\pi}$

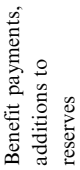

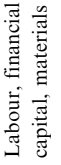

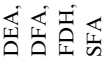

$\stackrel{0}{3}$

$\frac{\widetilde{\sigma}}{\infty}$

年

$\stackrel{\dot{\nu}}{\dot{D}}$

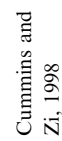

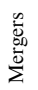

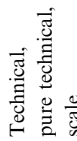

$\frac{\overrightarrow{0}}{0}$

$\stackrel{\frac{\pi}{7}}{>}$

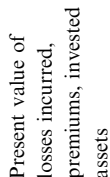

量

言兽

苗

尝

穿

ఫิ

\&

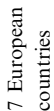

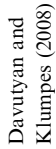

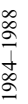

孛

章

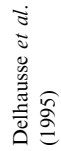

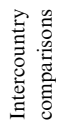

窇

$\overrightarrow{0}$
$\frac{0}{\pi}$
0
$\frac{0}{\pi}$

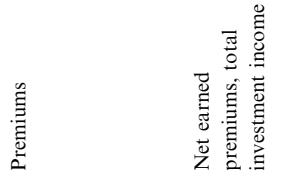

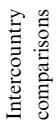

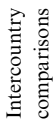

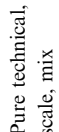
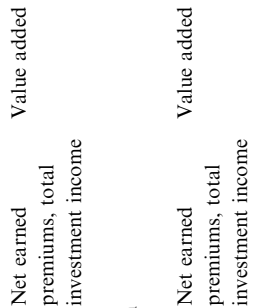

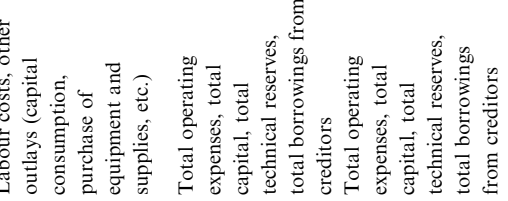

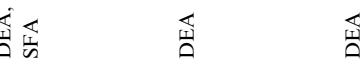

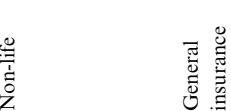

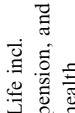

$\frac{\grave{\partial}}{\grave{b}}$

ڤे

$\bar{q} \quad \vec{g}$

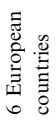

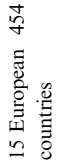

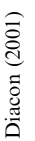




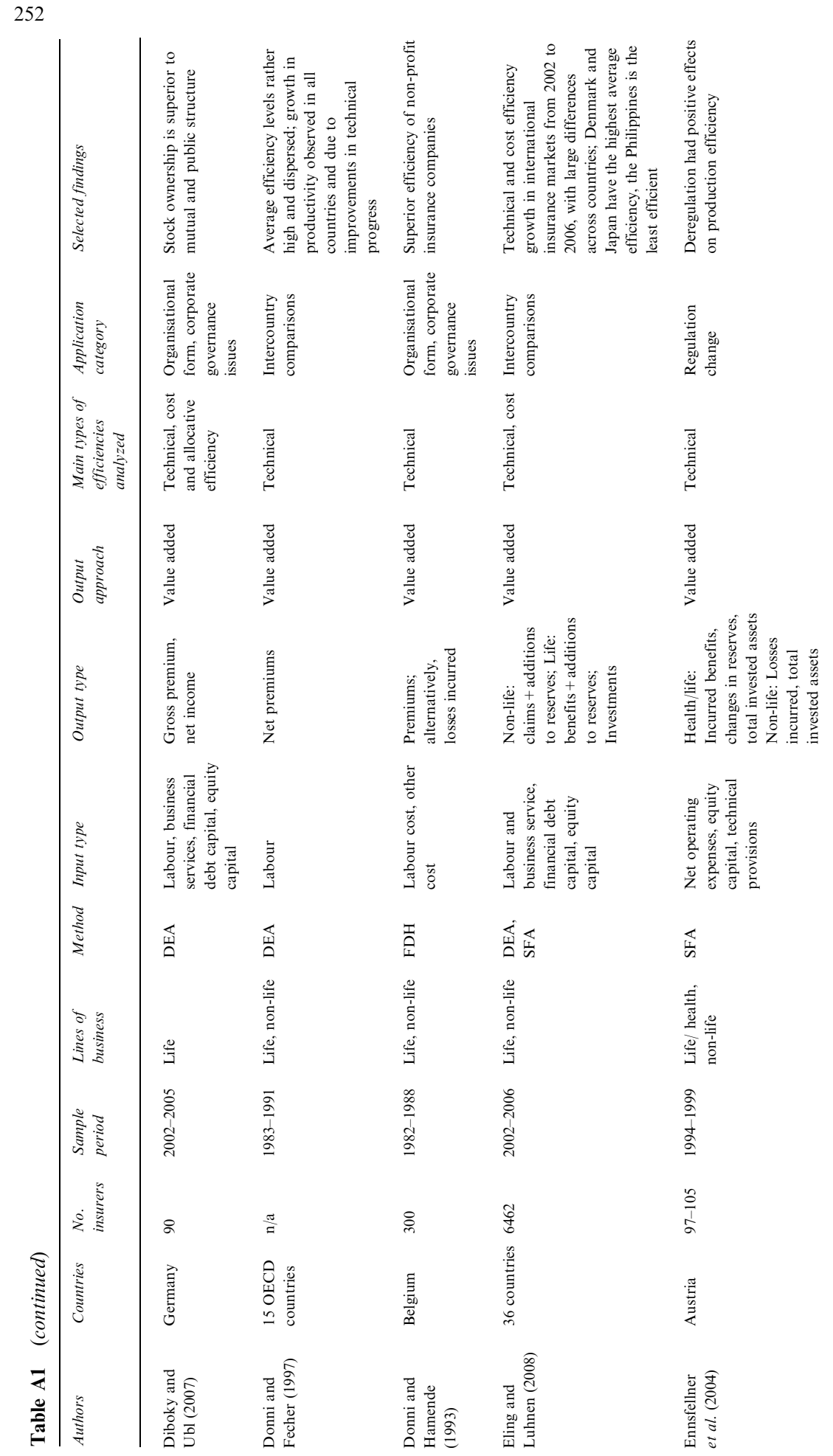



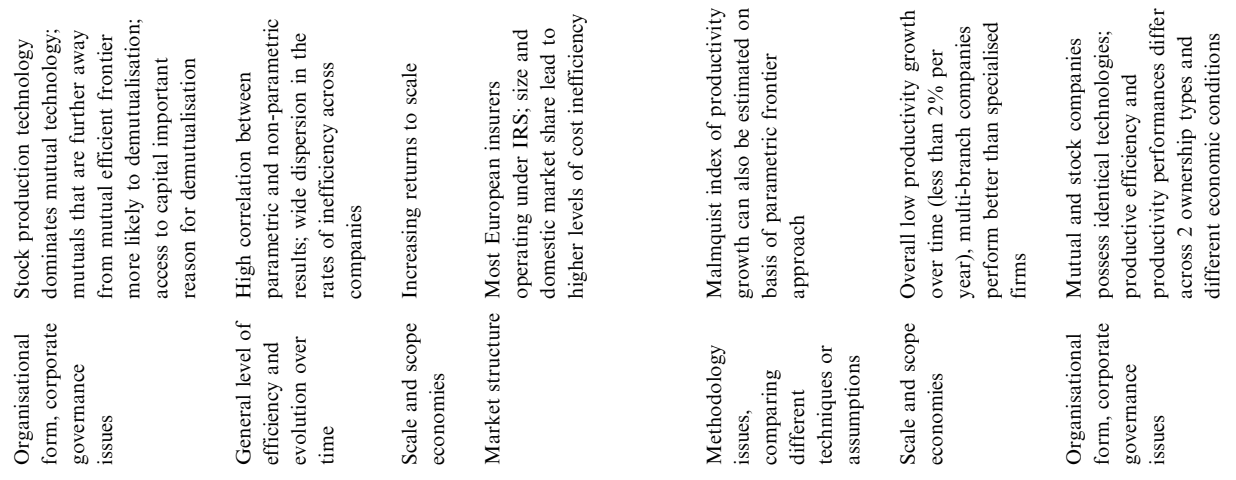

窇

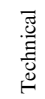

产

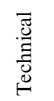

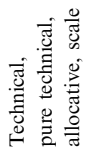

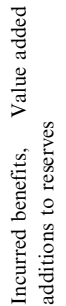

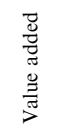

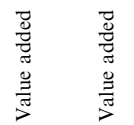

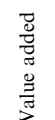

胥

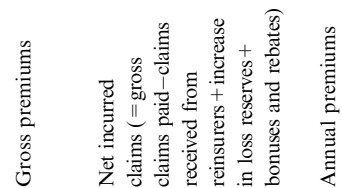

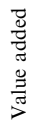

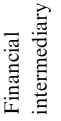

章
产
0
0
0
0
0

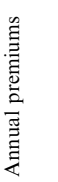

言

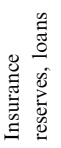

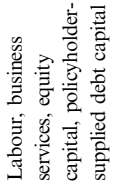

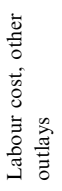

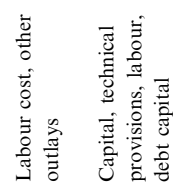

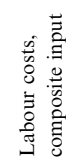

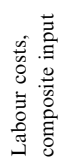

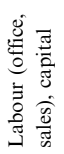

莘

离昰岳在

㭊

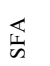

똠

$\stackrel{0}{\leftrightarrows}$

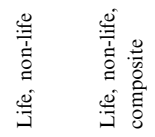

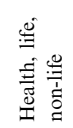

起

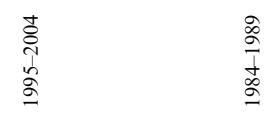

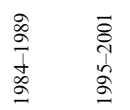

$\frac{+}{\frac{1}{2}}$

$\frac{\hat{\alpha}}{\frac{1}{\alpha}}$

$\stackrel{\varrho}{3}$

$\stackrel{\circ}{\circ}$

$\stackrel{?}{0}$

స్

굠

in

$\stackrel{3}{*}$

2

$\dot{2}$<smiles>[CH]1CCCC1</smiles>

竞.

है

ตั

善

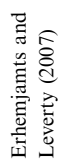

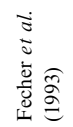

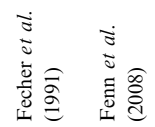

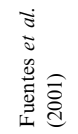

点

重空 


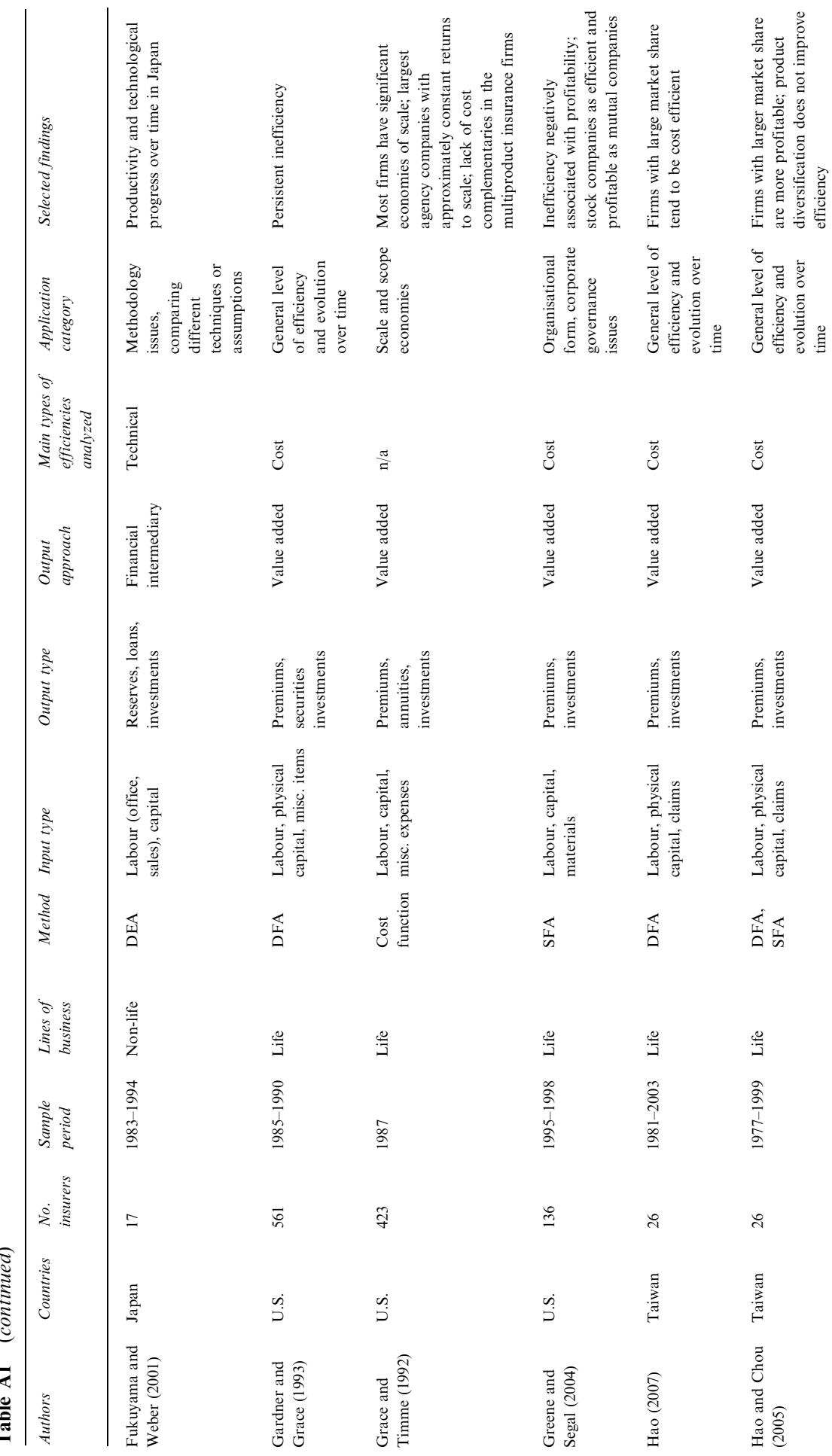




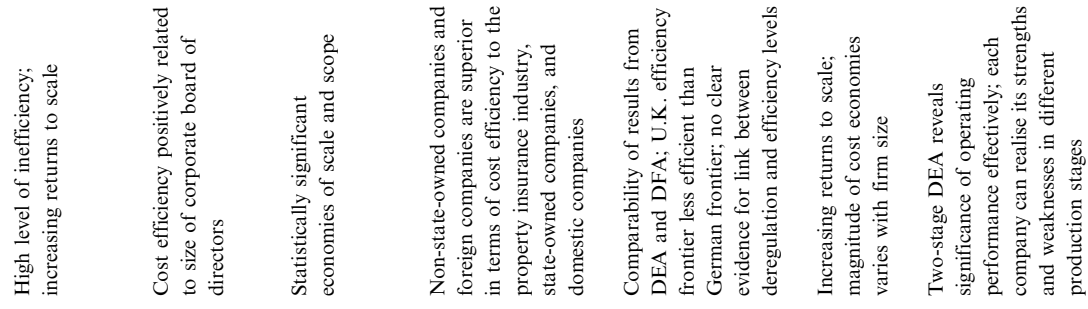

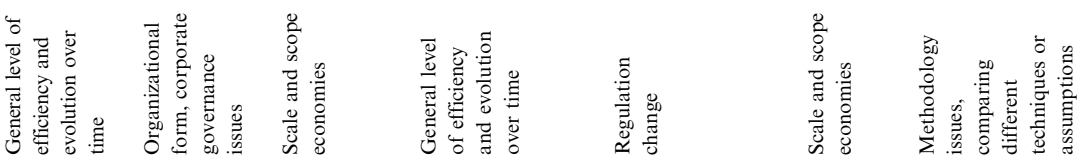

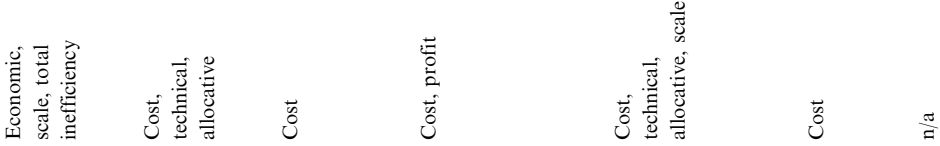

\begin{tabular}{|c|c|c|c|c|}
\hline 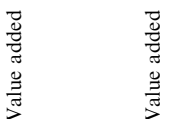 & 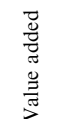 & 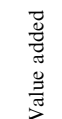 & 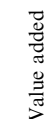 & 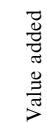 \\
\hline
\end{tabular}

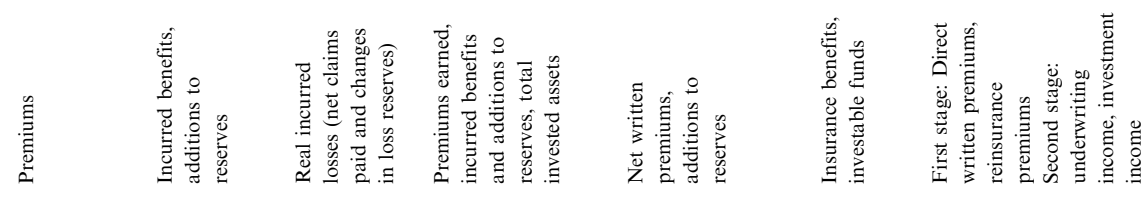

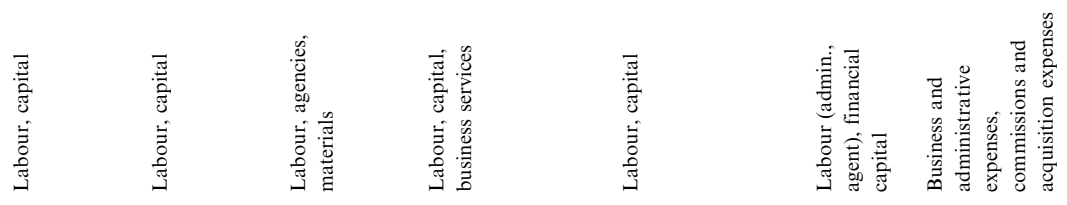

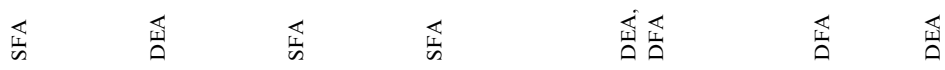

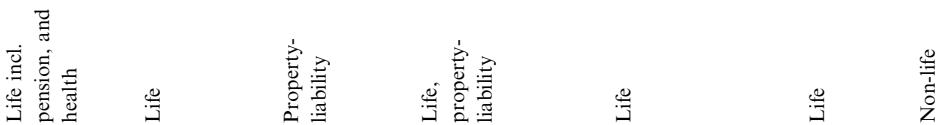

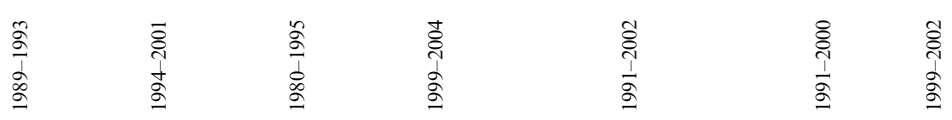

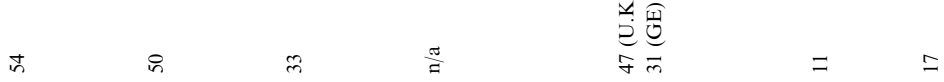

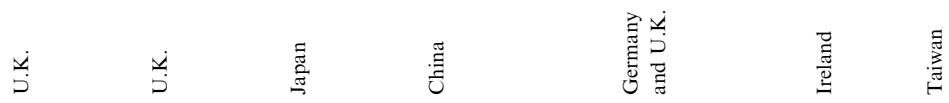

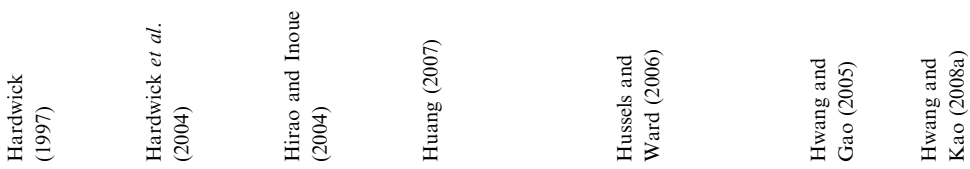




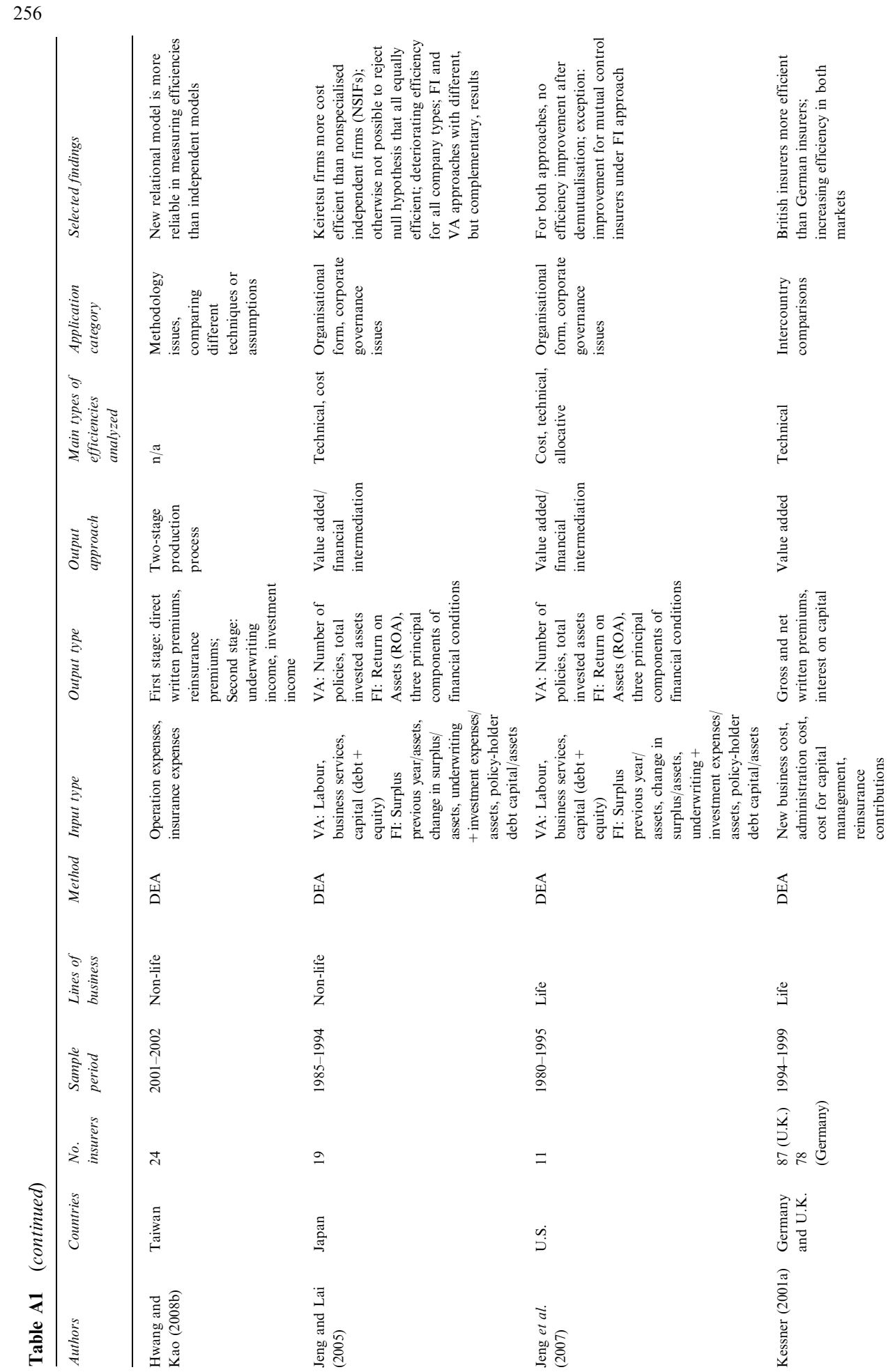



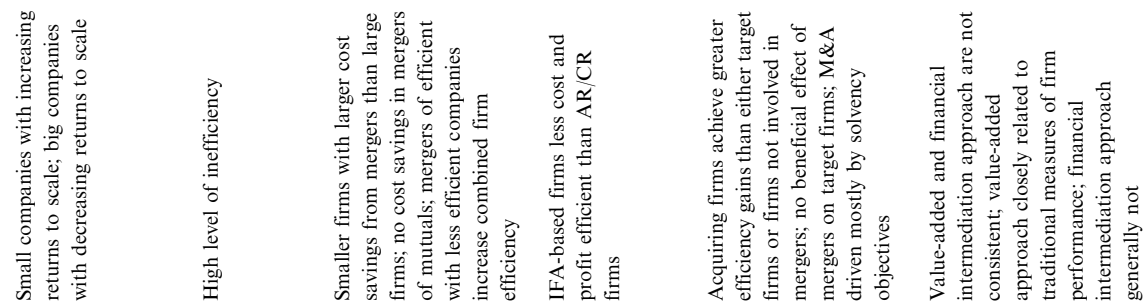

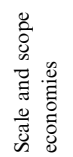

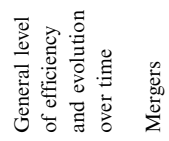

若

离

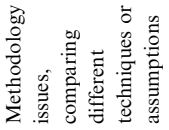

苞

苞

苑

$\overrightarrow{0}$
$\frac{0}{0}$
$\dot{0}$
0

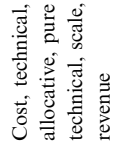

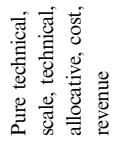

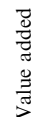

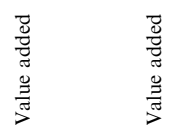

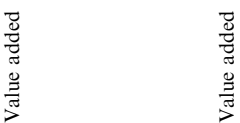

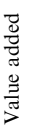

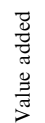

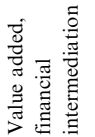

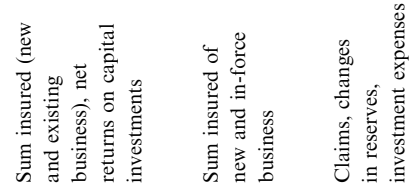

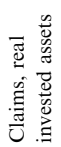
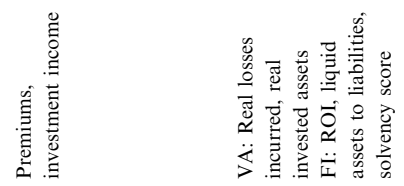

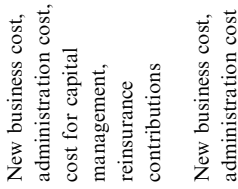

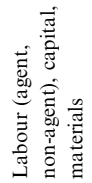

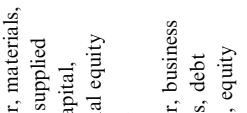

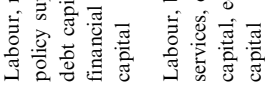

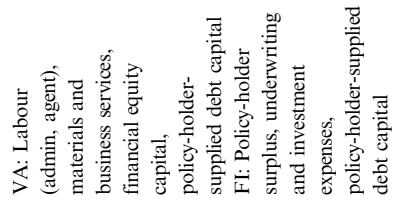

뚐

苗藏

苦

兽

獣

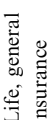

离:

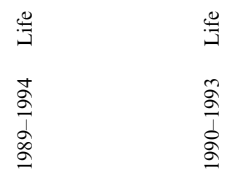

$\stackrel{0}{3}$

垉.

$\frac{2}{d}$

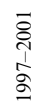

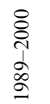

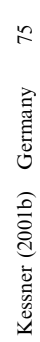

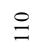

$\stackrel{\infty}{a}$

q

$\stackrel{\infty}{=}$

$\stackrel{\Xi}{\rightleftarrows}$

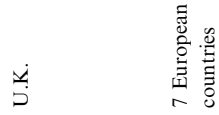

$\stackrel{\infty}{3}$

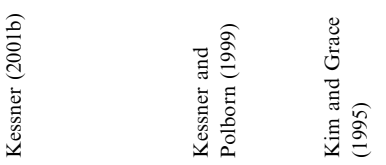

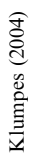

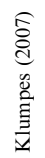




\begin{tabular}{|c|c|c|c|c|c|c|}
\hline 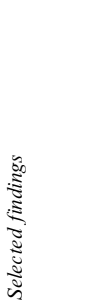 & 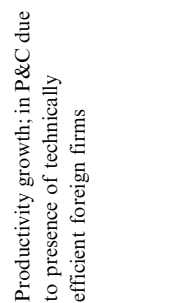 & 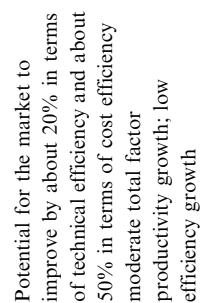 & 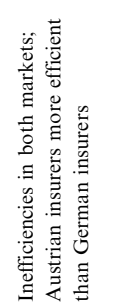 & 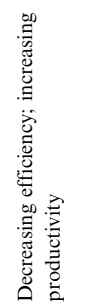 & 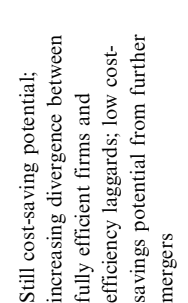 & 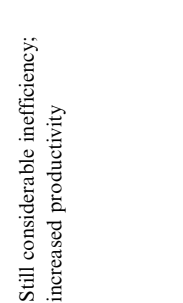 \\
\hline ปั & 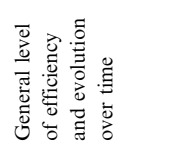 & 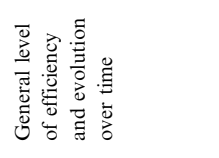 & 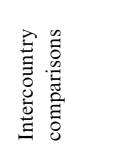 & 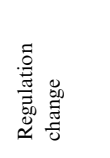 & 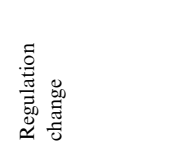 & 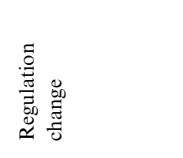 \\
\hline 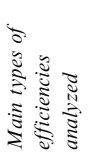 & 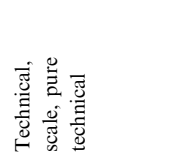 & 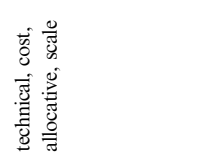 & . & 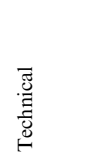 & 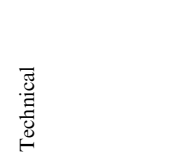 & 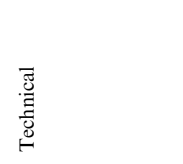 \\
\hline 竎 & 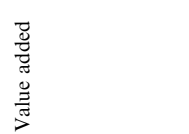 & 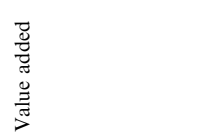 & 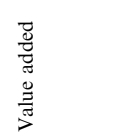 & 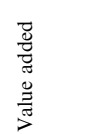 & 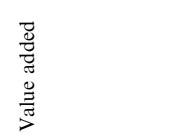 & 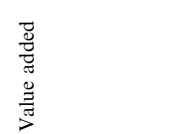 \\
\hline בั & 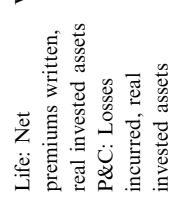 & 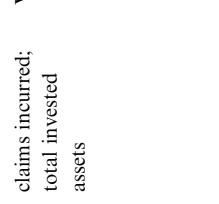 & 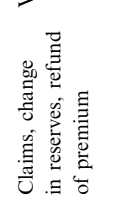 & 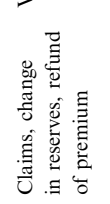 & 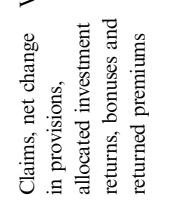 & 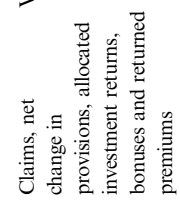 \\
\hline 气્气 & 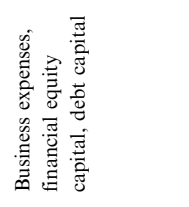 & 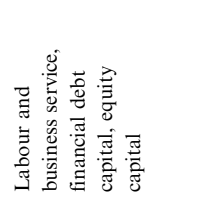 & 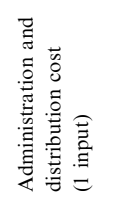 & 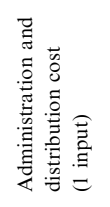 & 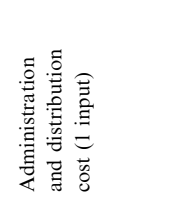 & 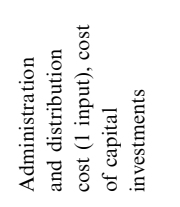 \\
\hline ฐั & 近 & 茴 & 知 & 音 & 晃 & 獣 \\
\hline 氙 & 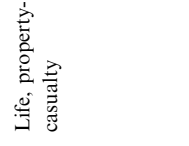 & 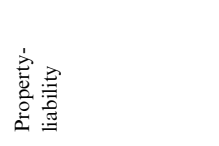 & 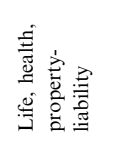 & 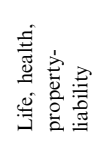 & 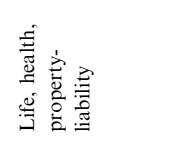 & 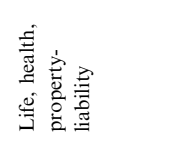 \\
\hline 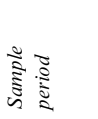 & $\begin{array}{l}\text { 今े } \\
\text { ते } \\
\alpha \\
\alpha\end{array}$ & 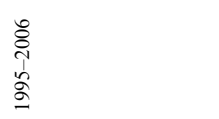 & 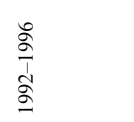 & 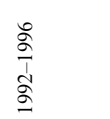 & $\begin{array}{l}\stackrel{0}{\circ} \\
\frac{1}{1} \\
\vdots \\
2\end{array}$ & $\begin{array}{l}\text { gे } \\
\frac{1}{1} \\
\text { gे }\end{array}$ \\
\hline 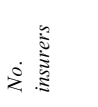 & $\begin{array}{l}\bar{\ddagger} \\
\underset{\sim}{\sim}\end{array}$ & ڤे & 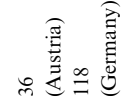 & 悉 & $\begin{array}{l}m \\
\tilde{n} \\
\dot{d}\end{array}$ & $\begin{array}{l}\text { p } \\
\text { ò }\end{array}$ \\
\hline 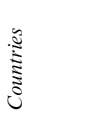 & 莺 & 胥 & 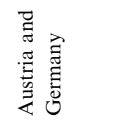 & 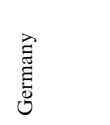 & 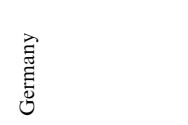 & 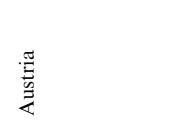 \\
\hline 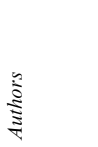 & 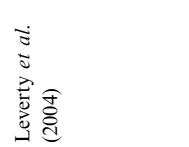 & 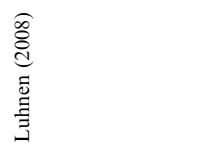 & 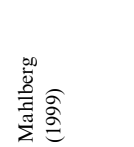 & 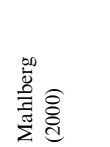 & 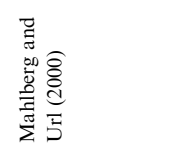 & 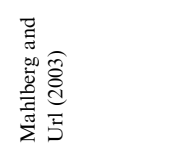 \\
\hline
\end{tabular}




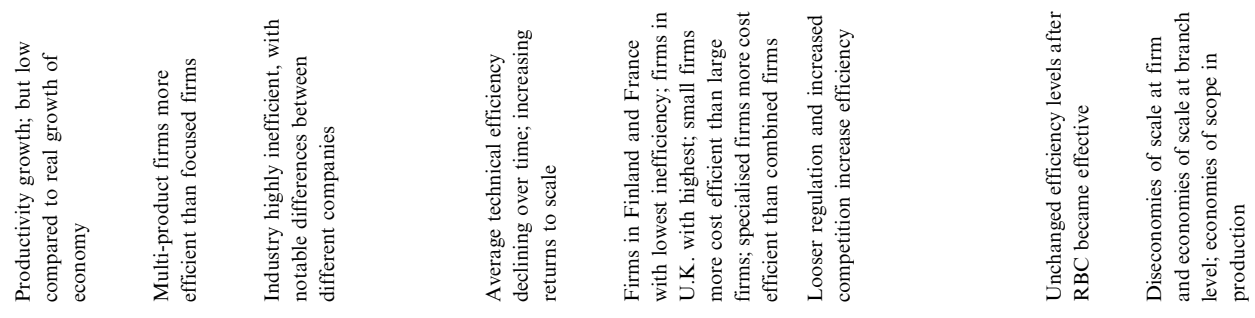

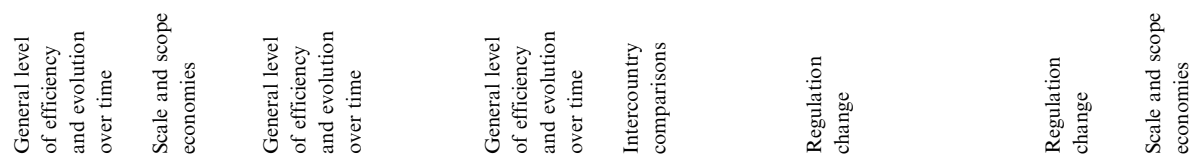

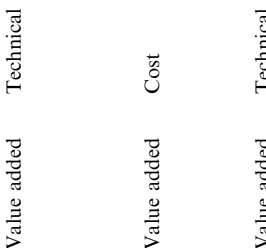

言 羿

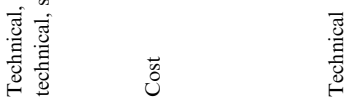

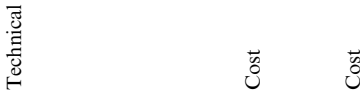

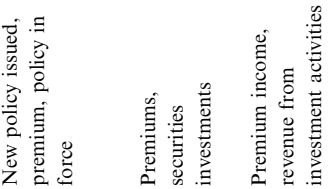

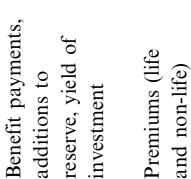

趂

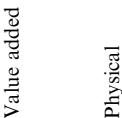

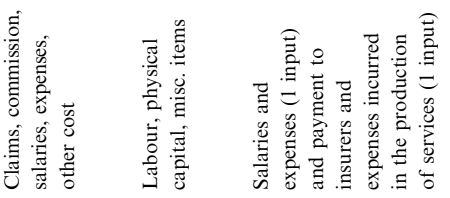

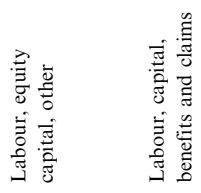

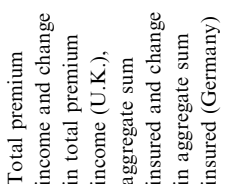

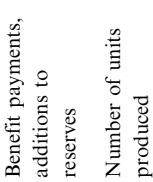

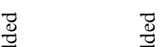

$\stackrel{\frac{0}{5}}{\frac{0}{2}}$

259

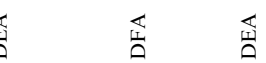

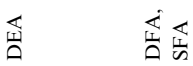

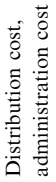

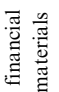

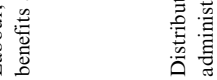

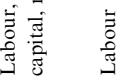

留

$\cong$

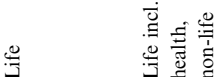

莘

岳岳

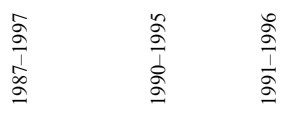

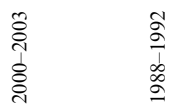

$\stackrel{2}{3}$

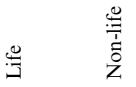

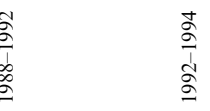

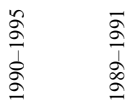

$\simeq \quad \infty$

$\stackrel{丶}{ \pm}$

$\bar{\pi} \quad \overline{4}$

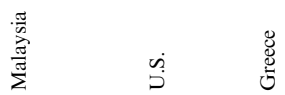

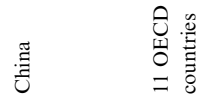

递

品 莺

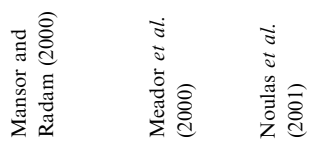

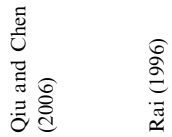

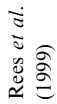

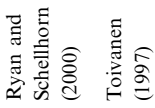




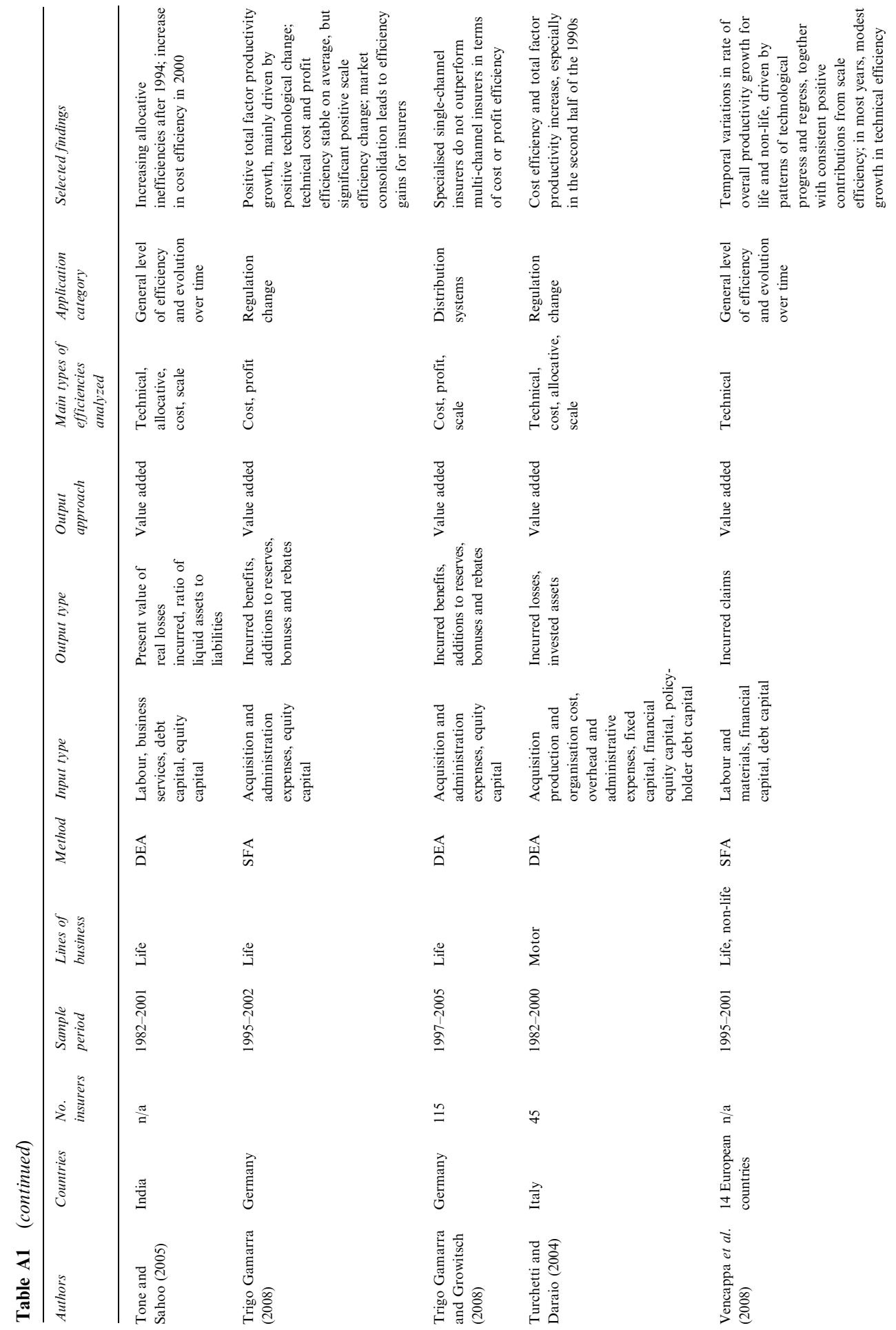




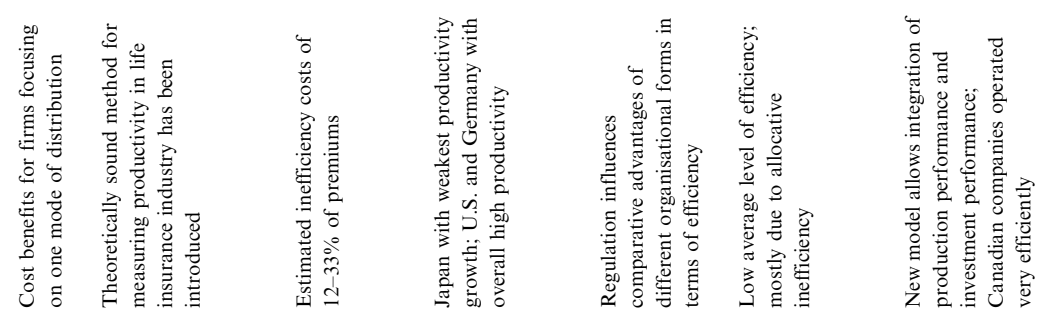

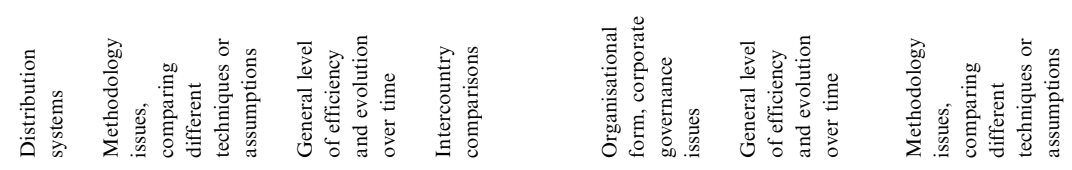

ฏ.

范范

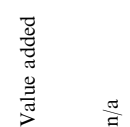

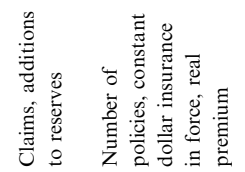

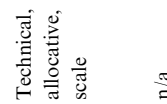

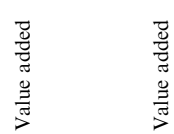

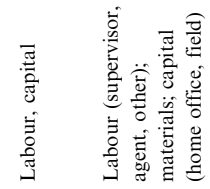

苦总

气

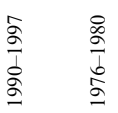

小

$\stackrel{4}{3}$

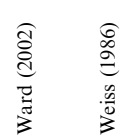

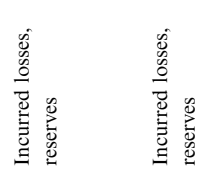

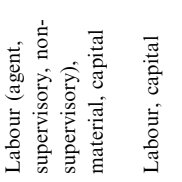

店旁

言高

言站

蒿

플

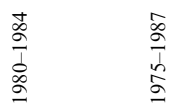

\&

s.

$\stackrel{5}{=}$

要

獣要

$\sum_{\substack{0 \\ \frac{\pi}{2}}}^{\frac{\pi}{2}}$
IIt

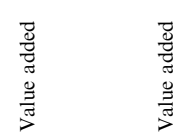

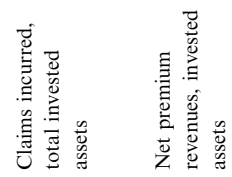

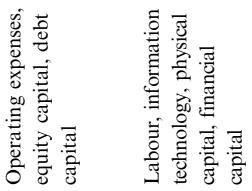

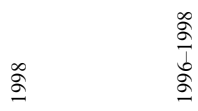

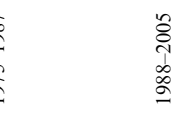

우

$\frac{\sqrt{2}}{2}$

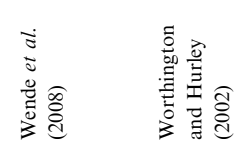

261 


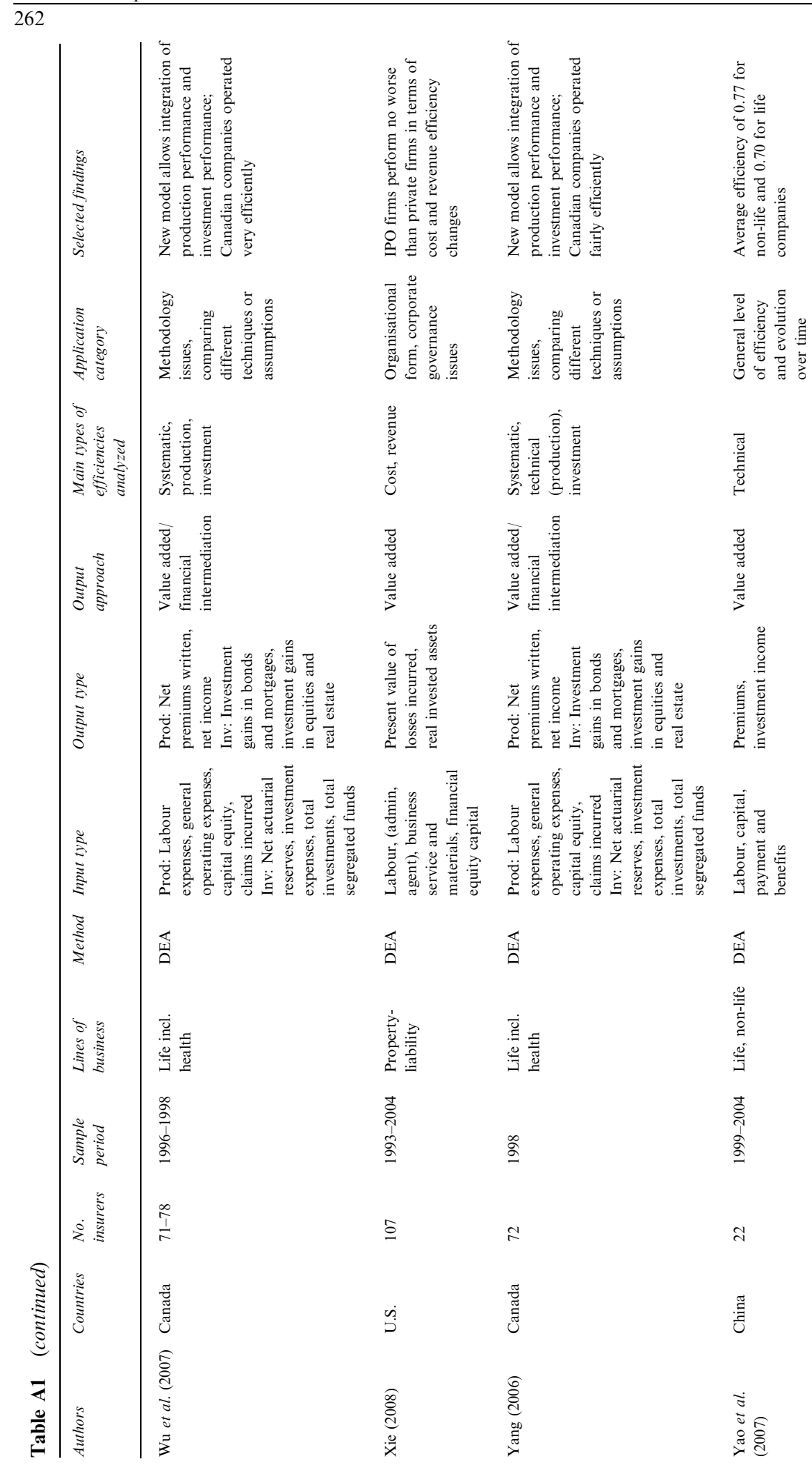




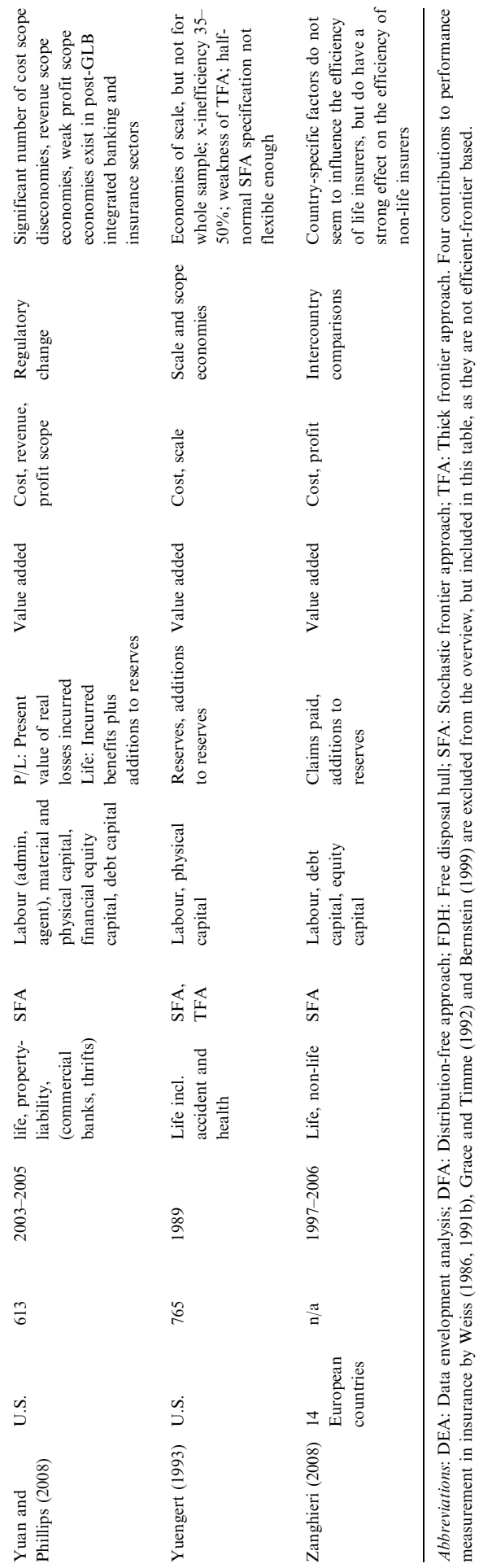




\section{Appendix B}

\section{Search strategy}

Our search strategy consists of four steps. Table B1 summarises these four steps and their most important elements (called sub-steps in Table B1).

Table B1 Search Strategy

\begin{tabular}{|c|c|c|}
\hline Number & Step & Sub-steps \\
\hline 1 & $\begin{array}{l}\text { Definition of the search } \\
\text { strategy }\end{array}$ & $\begin{array}{l}\text { 1.1. Define a list of relevant key words (based on the Cummins and } \\
\text { Weiss (2000); Berger/Humphrey (1997) surveys and other more } \\
\text { recent articles): Insurance, Efficiency, Productivity, Malmquist } \\
\text { Index, Data Envelopment Analysis, Stochastic Frontier } \\
\text { Analysis, ... } \\
\text { 1.2. Define a list of relevant authors: David Cummins, Mary Weiss, } \\
\text { Allen N. Berger, Maria Rubio-Misas, Sharon Tennyson, Martin } \\
\text { F. Grace, ... } \\
\text { 1.3. Define a list of relevant journals: The Geneva Papers on Risk and } \\
\text { Insurance, The Geneva Risk and Insurance Review, Journal of } \\
\text { Risk and Insurance, Risk Management and Insurance Review, } \\
\text { Journal of Productivity Analysis, European Journal of Operational } \\
\text { Research, Journal of Banking and Finance ... }\end{array}$ \\
\hline
\end{tabular}

2 Implementation of the search strategy (data collection)

Evaluation of search results

Revision and completion of search based on comments of colleagues/ on conferences
2.1. Search for articles in the relevant journals using the key words

2.2. Search for articles and working papers via Google Scholar using the key words (for example, "Data Envelopment Analysis" and Insurance, "Stochastic Frontier Analysis" and Insurance)

2.3. Search for articles via publication databases such as Social Science Research Network (http://www.ssrn.com/), EBSCO (http://ejournals.ebsco.com/), and Science Direct (http:// www.sciencedirect.com/) using the key words

2.4. Search for articles and working papers on the web pages of the relevant authors (David Cummins, Mary Weiss, ... ; especially in their list of publications)

2.5. Follow cross-references from overview sections of found papers

2.6. Attend and systematically scan conferences on frontier efficiency (e.g., JBF conference on "the Uses of Frontier Efficiency Methodologies for Performance Measurement in the Financial Services Sector") and insurance (e.g., ARIA annual meeting, EGRIE conference) to identify most recent working papers on the topic

3.1. Data preparation according to the categories published in the list in the Appendix A of the paper (authors, countries, number of insurers, sample period, lines of business covered, used methods, inputs and outputs used, types of efficiency analyzed, application category, selected findings)

3.2. Delete articles that are not efficient frontier based, but focus mostly on productivity or other aspects

3.3. Delete working papers that do not have sufficient quality

4.1. We have sent the manuscript including the list of papers to colleagues and asked them if there is something missing; additionally, presented search results at conferences and collected feedback

4.2. The feedback of the colleagues was integrated 
Table B2 Matrix-like review strategy for journals

\begin{tabular}{lllll}
\hline Keywords & Efficiency & Productivity & $\begin{array}{l}\text { Data } \\
\text { envelopment } \\
\text { analysis }\end{array}$ & $\begin{array}{l}\text { Stochastic } \\
\text { frontier } \\
\text { analysis }\end{array}$ \\
\hline
\end{tabular}

Journals

Geneva papers on Risk and Insurance

Geneva Risk and Insurance Review

Insurance: Mathematics and Economics

Journal of Risk and Insurance

Risk Management and Insurance Review

...

The first step was to define a search strategy based on a list of keywords, journals, and authors. In the second step we implemented the search strategy, that is, we systematically scanned the relevant literature for articles and working papers. For the journals this resulted in a matrix-like review strategy as presented in Table B2. Important here was, however, not to restrict on existing authors and journals in the field, but to have a broader focus including a Google Scholar search and a search in the publication databases such as EBSCO and Science Direct. An element of step 2 also was to attend relevant academic conferences, both on frontier efficiency and on risk management and insurance. The third step then was to systematically analyse the found articles on a set of predefined criteria. This step resulted in the large table presented in Appendix A of this paper. Here we have deleted articles that are not efficient frontier based, but focus on productivity or other aspects. We have also deleted articles that were not of convincing quality (for example, we found many working papers with inaccurate and incorrect presentation in terms of methodology and language and decided not to integrate these in our review; all these articles are, of course, available upon request). Finally, we sent the paper to colleagues in order to receive some feedback, especially in terms of completeness. After integrating the comments from colleagues, we ended up with a list of 95 working papers (Table A). 